\title{
Computational Analysis of Pitch Stability for a Slotted Airfoil in Ground Effect
}

\author{
Meagan L. Hubbell \\ West Virginia University
}

Follow this and additional works at: https://researchrepository.wvu.edu/etd

\section{Recommended Citation}

Hubbell, Meagan L., "Computational Analysis of Pitch Stability for a Slotted Airfoil in Ground Effect" (2008). Graduate Theses, Dissertations, and Problem Reports. 4382.

https://researchrepository.wvu.edu/etd/4382

This Thesis is protected by copyright and/or related rights. It has been brought to you by the The Research Repository @WVU with permission from the rights-holder(s). You are free to use this Thesis in any way that is permitted by the copyright and related rights legislation that applies to your use. For other uses you must obtain permission from the rights-holder(s) directly, unless additional rights are indicated by a Creative Commons license in the record and/ or on the work itself. This Thesis has been accepted for inclusion in WVU Graduate Theses, Dissertations, and Problem Reports collection by an authorized administrator of The Research Repository @ WVU. For more information, please contact researchrepository@mail.wvu.edu. 


\title{
Computational Analysis of Pitch Stability for a Slotted Airfoil in Ground Effect
}

\author{
Meagan L. Hubbell
}

Thesis submitted to the College of Engineering and Mineral Resources

at West Virginia University

in partial fulfillment of the requirements

for the degree of

Master of Science

in

Aerospace Engineering

Dr. James Smith, PhD., Committee Chair

Dr. Benjamin Shade, PhD.

Dr. Hailin Li, PhD.

Department of Mechanical and Aerospace Engineering

\author{
Morgantown, West Virginia \\ 2008
}

Keywords: Ground Effect, Pitch Stability, Passive Control

Copyright 2008 Meagan L. Hubbell 


\section{Abstract \\ Computational Analysis of Pitch Stability for a Slotted Airfoil in Ground Effect}

\section{Meagan L. Hubbell}

Ground effect is a phenomenon which occurs when flow is displaced around a moving body in close proximity to the ground. This displacement is caused by compressed air that becomes trapped during motion between the body and the ground. The added upward thrust caused by ground effect can be used to generate and augment lift on a small aircraft. AirRay is a small single person, recreational downhill glider that operates within this ground effect. When launched from the top of a hill, it can glide to the base using ground effect for lift.

One of the amplified effects of operating close to the ground is a shifting centerof-pressure. This effect, exacerbated by the changing ground roughness and varying passenger size, can create an unstable pitch contributing to the complexity of the vehicle's control. To minimize the control requirements necessitates the stabilization and restriction in the movement of the center-of-pressure.

To restrict the movement of the center-of-pressure, patent pending slots will be used to modify the airfoil surfaces. Through computational analysis, the effects of slots and their placement on the aerodynamic characteristics will be determined as well as the optimal conditions for pitch stability. Computational fluid dynamics (CFD) will be used to compare the effects of placing a slot on a two dimensional Wortmann FX63-137 airfoil in ground effect. The Wortmann FX63-137 is a low speed airfoil with a high coefficient 
of lift that is commonly used on sail planes and is ideally suited for AirRay. The geometric shape of the slot will vary according to the angle of the slot with respect to the chord line and the position of the slot along the chord line. In addition, the analysis will include five different angles of attack: $-3^{\circ}, 0^{\circ}, 5^{\circ}, 10^{\circ}$, and $15^{\circ}$ in order to determine the effects on the aerodynamic characteristics.

In order to perform the computational analysis, 2-D models of the airfoil with the different types of slots will be created in Gambit. These were uploaded to Fluent and tested in a turbulence simulation which is representative of the environment for which AirRay is being designed. From these results, the optimal modifications for controlling the center-of-pressure and therefore the pitch were determined. The $x-20, d-40, w-2$ slot configuration was able to control the travel of the center-of-pressure $14 \%$ more effectively than the baseline airfoil. 


\title{
Acknowledgements
}

I would like to take this opportunity to express my gratitude to my committee members: Dr. Hailin Li, Dr. Benjamin Shade and Dr. James Smith, for their guidance and technical review of my thesis.

I would also like to thank my research advisor, Dr. James Smith, for his patience and support of all my crazy ideas and exuberant nature. He believed in my ability to succeed and had the willingness to give me a chance.

I would like to extend my appreciation to the CIRA members, especially Emily Pertl, Jon Kweder and Chad Panther, who have been there when I needed advice, assistance or just someone to talk to.

I would especially like to thank my family and friends for their enthusiasm, motivation and unending support of my goals in life without which all this would not be possible. Thank you, Mom and Dad!

\author{
“One doesn’t discover new lands \\ without consenting to lose sight of the shore \\ for a very long time.” \\ Andre Gide
}




\section{Table of Contents}

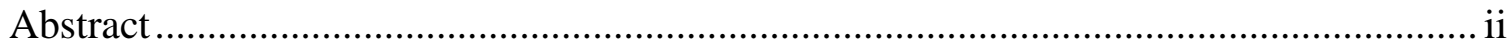

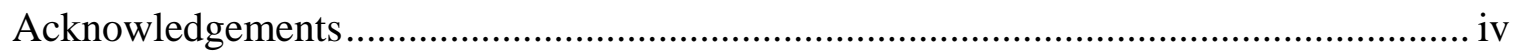

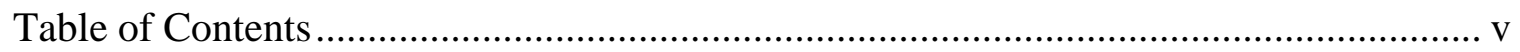

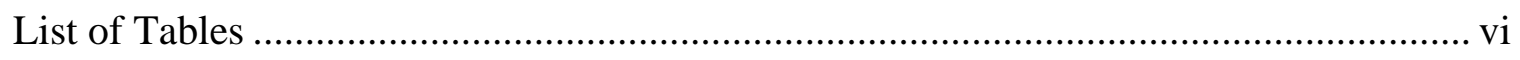

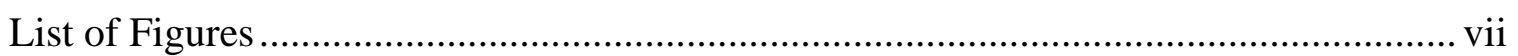

List of Symbols ................................................................................................. viii

List of Nomenclature .............................................................................................. viii

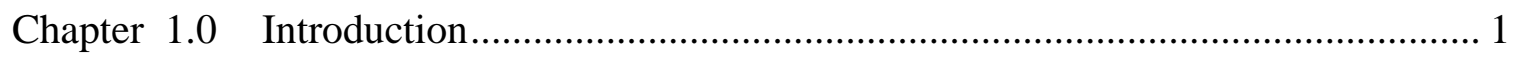

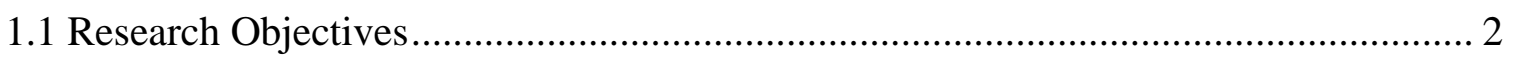

Chapter 2.0 Literature in Review .......................................................................... 4

2.1 Wing in Ground Effect Application.......................................................................... 4

2.2 Numerical Wing-in-Ground-Effect Research .................................................. 7

2.3 Experimental Wing-in-Ground-Effect Research ................................................... 8

2.4 Computational Wing-in-Ground-Effect Research ................................................ 11

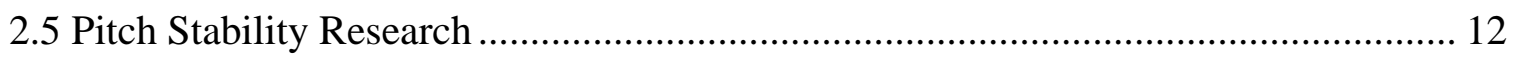

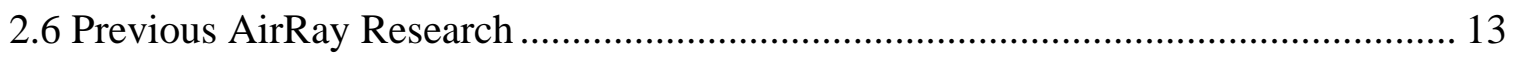

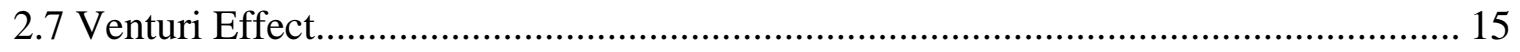

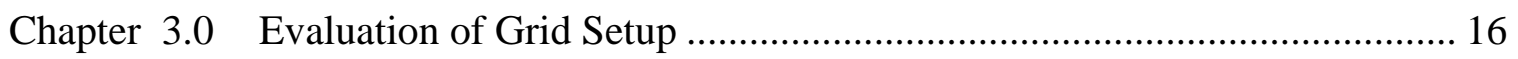

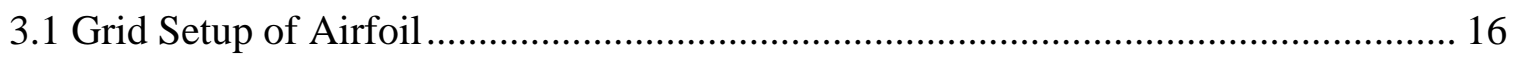

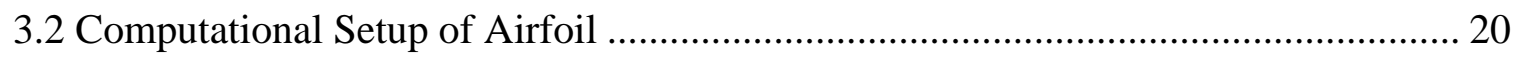

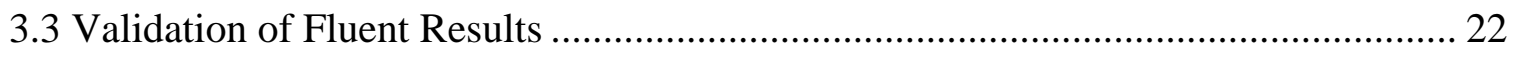

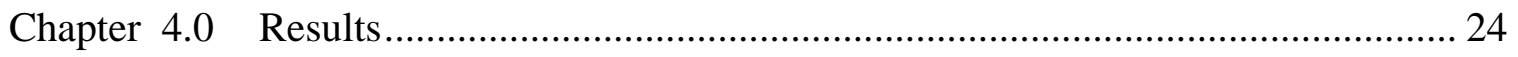

4.1 Analysis of Initial Convergence Data ................................................................ 24

4.2 Analysis of Secondary Convergence Data.............................................................. 30

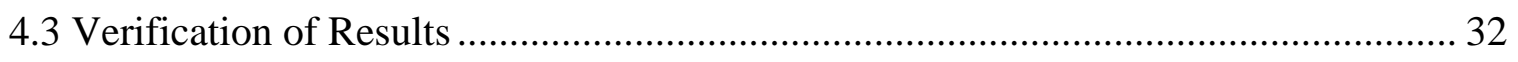

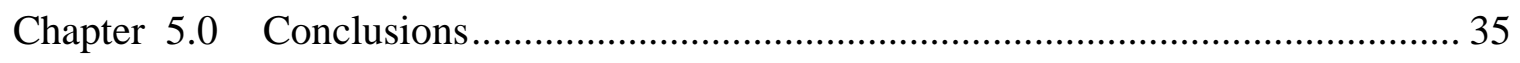

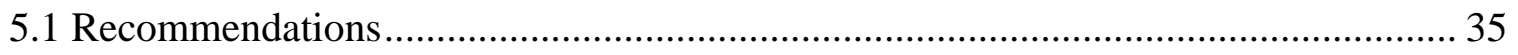

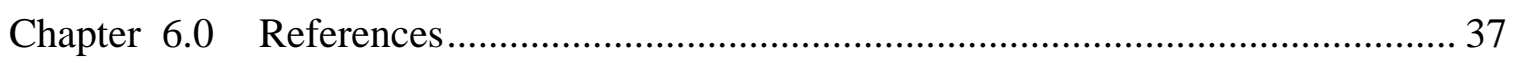

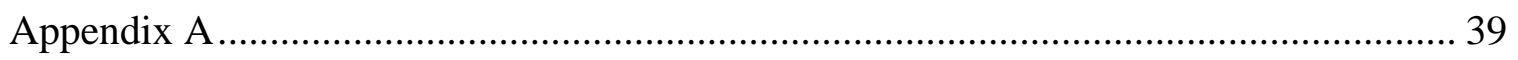

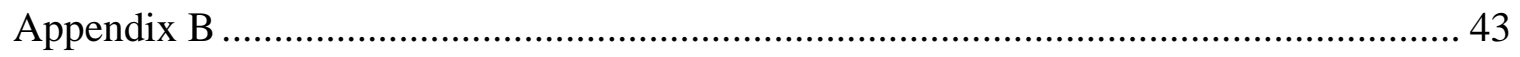

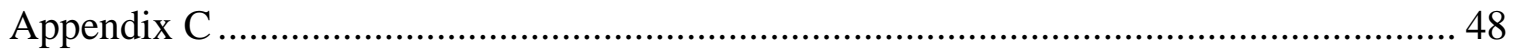




\section{List of Tables}

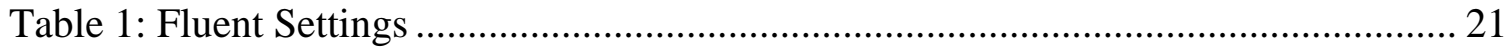

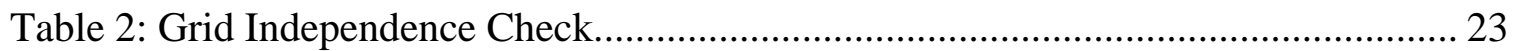

Table 3: Baseline Center-of-Pressure Data................................................................. 28

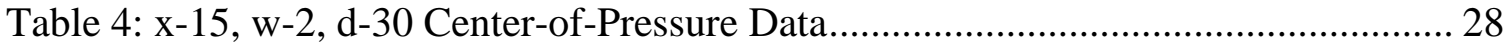

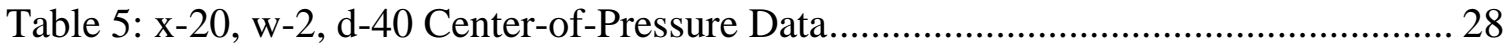

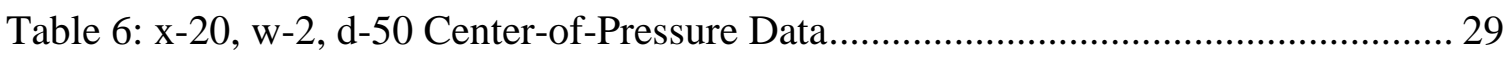

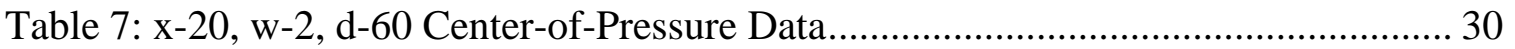

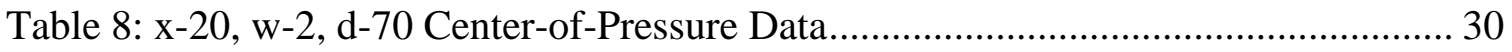

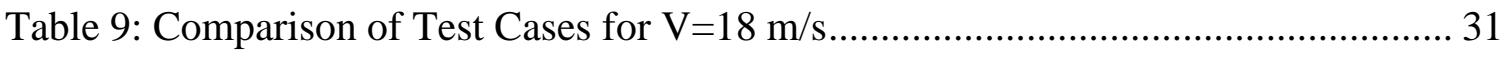

Table 10: Comparison of Additional Test Cases for $\mathrm{V}=18 \mathrm{~m} / \mathrm{s}$.................................... 31 


\section{List of Figures}

Figure 1: Artist Conception of AirRay [1] ................................................................. 2

Figure 2: Representation of Slot Characteristics ...................................................... 3

Figure 3: Ekranoplan Lowboy developed by Boeing [6] ............................................... 5

Figure 4: Ekranoplan Large Weilandcraft developed by Weiland [6].............................. 5

Figure 5: Collection of Russian Ekranoplan Designs [2] ............................................. 6

Figure 6: Boeing Pelican by Phantom Works [7] ....................................................... 7

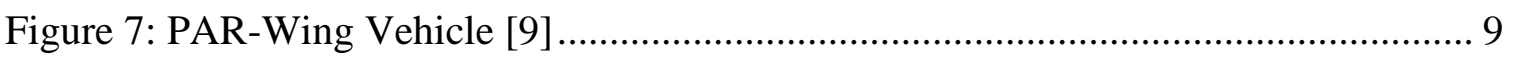

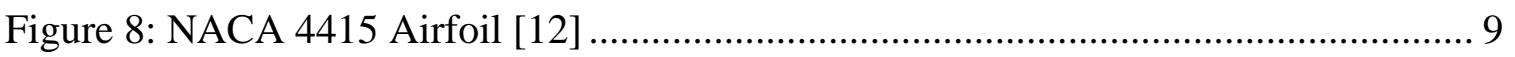

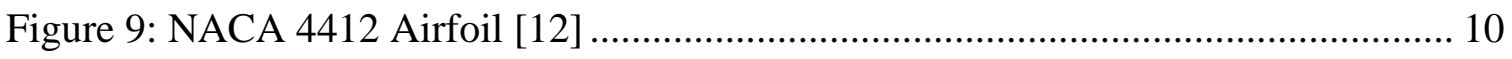

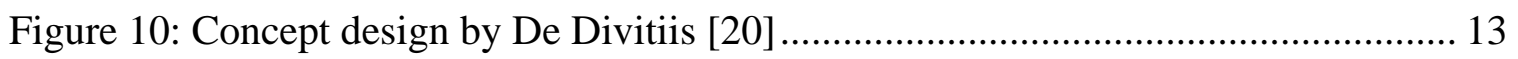

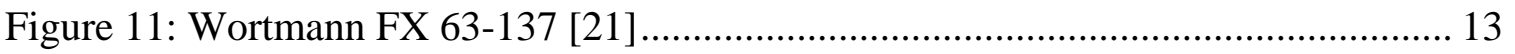

Figure 12: Wortmann FX 63-137 Aerodynamic Data [21] ........................................... 14

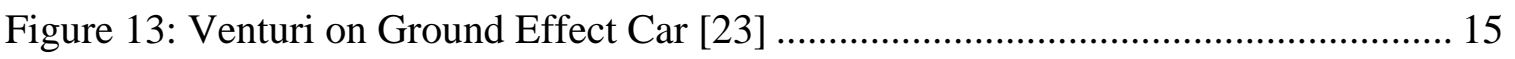

Figure 14: Wortmann FX 63-137 Baseline Model ........................................................ 17

Figure 15: Wortmann FX 63-137 Slotted Model........................................................... 17

Figure 16: Close-up of Slotted Model with Mesh ......................................................... 18

Figure 17: Wortmann FX 63-137 Slotted Model with Mesh......................................... 19

Figure 18: Max Travel of Baseline Xcp across AOA as \% of Chord.............................. 24

Figure 19: Average Travel of Xcp across AOA as \% of Chord ..................................... 25

Figure 20: Baseline Travel of Xcp Along Chord Length with respect to AOA ............... 26

Figure 21: Static Pressure Distribution of Baseline Model at V=18 m/s....................... 27

Figure 22: Comparative Analysis of Results with Previous Research ........................... 33

Figure 23: Comparative Analysis of Freestream Results ............................................ 34

Figure 24: Baseline A-0, V-18 - Pressure Distribution .................................................. 44

Figure 25: Baseline A-0, V-18 - Convergence of Lift Coefficient ................................ 44

Figure 26: Baseline A-5, V-18 - Pressure Distribution ................................................ 45

Figure 27: Baseline A-5, V-18 - Convergence of Lift Coefficient ................................ 45

Figure 28: Baseline A-10, V-18 - Pressure Distribution............................................... 46

Figure 29: Baseline A-10, V-18 - Convergence of Lift Coefficient .............................. 46

Figure 30: Baseline A-15, V-18 - Pressure Distribution............................................. 47

Figure 31: Baseline A-15, V-18 - Convergence of Lift Coefficient .............................. 47 


\section{List of Symbols}

$\begin{array}{ll}V & \text { Velocity } \\ \mu & \text { Viscosity } \\ \rho & \text { Density }\end{array}$

\section{List of Nomenclature}

$\begin{array}{ll}\text { AOA } & \text { Angle of Attack } \\ \text { CAD } & \text { Computer Aided Design } \\ \text { Cd } & \text { Coefficient of Drag } \\ \text { Cl } & \text { Coefficient of Lift } \\ \text { CFD } & \text { Computational Fluid Dynamics } \\ \text { CIRA } & \text { Center for Industrial Research Applications } \\ \text { D } & \text { Drag } \\ \text { FX } & \text { Force in x-direction } \\ \text { Fy } & \text { Force in y-direction } \\ \text { H } & \text { Height } \\ \text { M } & \text { Moment } \\ \text { NACA } & \text { National Advisory Committee for Aeronautics } \\ \text { PAR } & \text { Power Augmented Ram } \\ \text { Re } & \text { Reynolds Number } \\ \text { WIG } & \text { Wing in Ground Effect } \\ \text { Xcp } & \text { Position of Center-of-Pressure }\end{array}$




\section{Chapter 1.0 Introduction}

In recent years, an interest has developed in the field of ground effect gliders for use by the recreational industry. Ground effect is a phenomenon in which air flow is displaced around a moving body that is in close proximity to the ground. This effect is caused by air that becomes compressed and then trapped during motion causing an increase in the upward thrust exerted on the body. One such aircraft that uses this phenomenon to its advantage is AirRay, a small, single person downhill glider. The normal lift for this aircraft is augmented from ground effect, with gravity being used as the means of propulsion when launched from the top of a hill.

The concept for this design was derived from the flight capabilities of a pelican over oceanic waves. Like most coastal birds, pelicans use the aerodynamic characteristics that are present near the crest of waves to glide over the water's surface without flapping their wings. The forces experienced by pelicans on the water's surface are similar to those experienced by aircraft in ground effect.

AirRay was initially designed to be used on downhill ski slopes that are commonly not in use during the summer season. This would allow the resort industry with secondary means of income during the summer season. The conceptual design shown in Figure 1 is a base model that could potentially fit the needs of those costumers. 


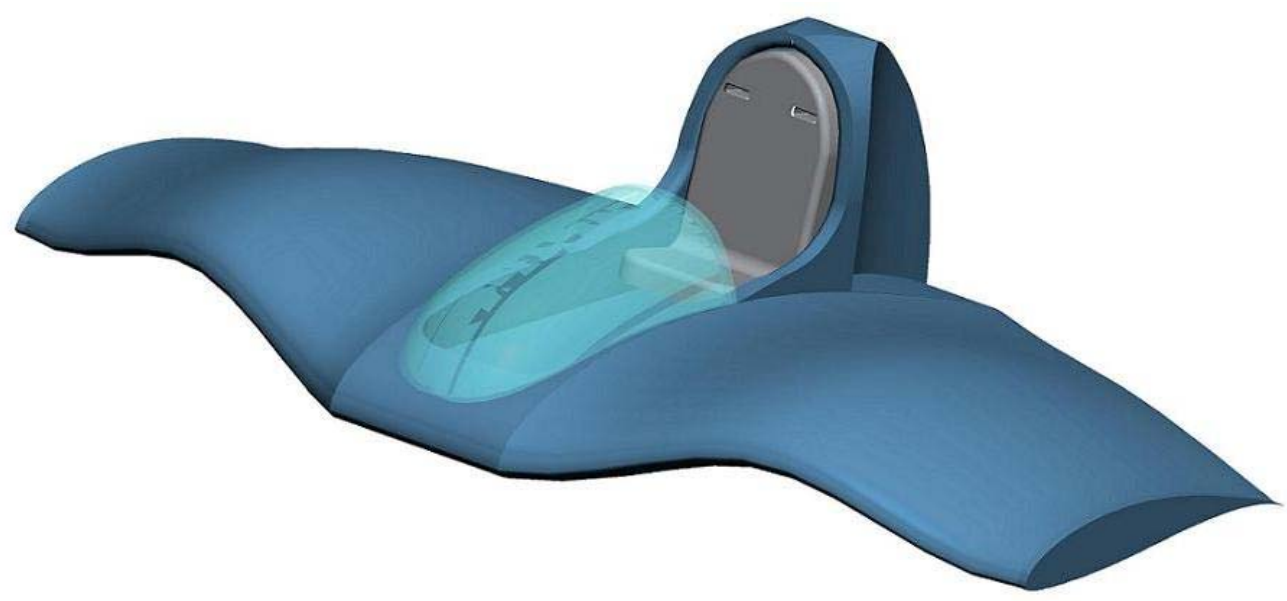

Figure 1: Artist Conception of AirRay [1]

This design has an approximate $12 \mathrm{ft}$ wing span with a center chord length of $10 \mathrm{ft}$ and a tip chord length of $6 \mathrm{ft}$. The craft itself weighs approximately 75-100 lbs with a possible passenger weight of up to 250 lbs.

A primary design concern is the safety of the passengers within the aircraft. Due to the shifting weight of the passengers and the varying angles of attack that the vehicle will experience, the center-of-pressure will constantly change causing a pitching moment. This pitching moment can lead to the aircraft leaving the ground effect regime and/or potentially rolling the aircraft nose-over-tail. Both of these possibilities emphasize the need for control over the aerodynamic characteristics, particularly the center-of-pressure, in order to achieve stable and safe flight.

\subsection{Research Objectives}

The main objective of this research is to restrict the travel of the center-ofpressure through the use of passive controls creating longitudinal stability for varying angles of attack. Pressure equalization slots will be used as a means to passively control 
this center-of-pressure movement which could potentially be placed at varying positions along the chord of the airfoil in order to redirect the airflow at higher angles of attack. Pitch stability is vital to the flight of an aircraft, especially in such close proximity to the ground where the craft could potentially pitch into the ground, aerodynamically stall, or pitch backwards.

The slots will be evaluated based on two main parameters: the angle of the slot with respect to the normal of the chord line $\left(d=20^{\circ}, 30^{\circ}\right.$, and $\left.40^{\circ}\right)$ and the position of the slot along the chord line from the leading edge $(x / c=0.15,0.20$, and 0.25$)$ as shown in Figure 2. In addition, these airfoils will be tested at three velocities: 8, 12, and $18 \mathrm{~m} / \mathrm{s}$. These are representative of the average and maximum design speeds of the glider under normal operating conditions and the projected maximum speed for the final glider design.

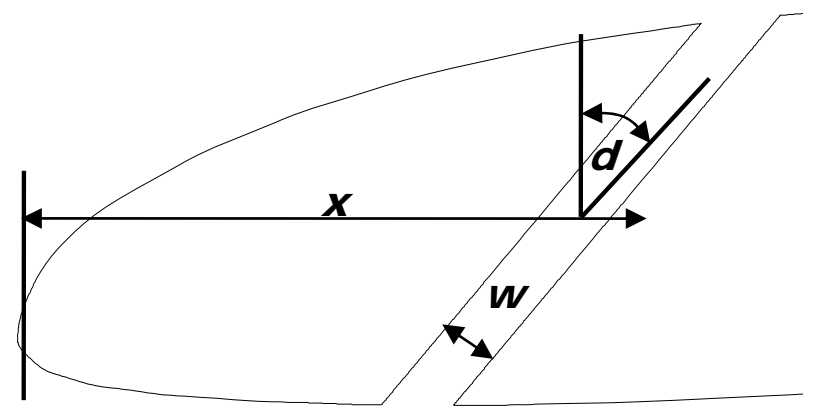

Figure 2: Representation of Slot Characteristics

These models will be computationally tested in CFD and compared against baseline testing of the Wortmann FX 63-137 which has been both theoretically and computationally modeled in previous research. 


\section{Chapter 2.0 Literature in Review}

This chapter discusses previous research that has been performed in the areas of ground effect and the use of passive controls to alter the aerodynamic characteristics of an airfoil.

Ground effect is understood to be an increase in the lift-to-drag ratio of a lifting surface (a wing) moving close to the ground. Research into ground effect initially began in the 1930s but it was not until much later that the development of ground effect vehicles actually occurred. [2]

There are two primary types of ground effect, span dominated and chord dominated. Chord dominated ground effect is associated with pronounced stagnation underneath the wing [2]. This usually results in an increase of pressure under the moving body while in close proximity to the ground [3]. The span dominated ground effect is used when considering the aerodynamics of a wing of large aspect ratio where the chord and ground clearance are much less than the span. A prominent result of the span dominated ground effect is the reduction of the induced drag [3]. Though these effects were initially associated with ground cushioning, pitch instability was also eventually recognized as an inherent feature of wing-in-ground-effect vehicles [2].

\subsection{Wing in Ground Effect Application}

In the early 1930s ground effect was found to be a prominent influence on aircraft aerodynamics when in close proximity to the ground. This became especially apparent during a service flight of a Dornier DO-X seaplane across the Atlantic Ocean. It was capable of increasing its payload and range when flying particularly close to the water 
[2]. Ground effect, however, was used as early as the 1900s with the Wright Brother's early manned tests [4].

Investigation began into ground effect machines in the later 1930s, but experimental testing was limited to fixed ground boards placed near the surface of the airfoil inside of a wind tunnel [5]. There were few practical applications during this time, the most famous of these being a high speed snow sleigh developed in Sweden [4].

Further research was stalled until the later development of ekranoplans. Ekranoplans are defined as vehicles that are heavier than air and contain at least one engine, which are capable of flying close to an underlying surface for utilization of ground effect [2]. Such planes include the "Lowboy" by Boeing [6] as shown in Figure 3 and the "Large Weilandcraft" by Weiland [6] as shown in Figure 4.

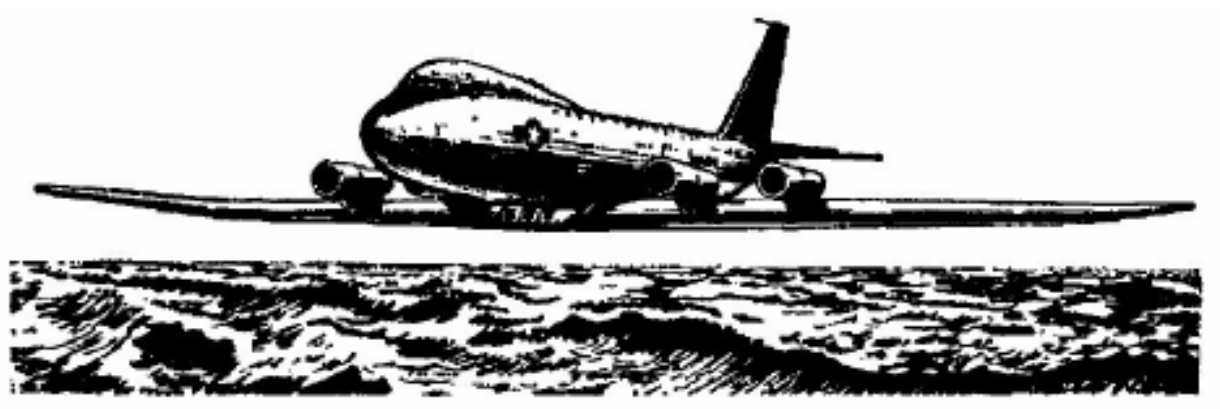

Figure 3: Ekranoplan Lowboy developed by Boeing [6]

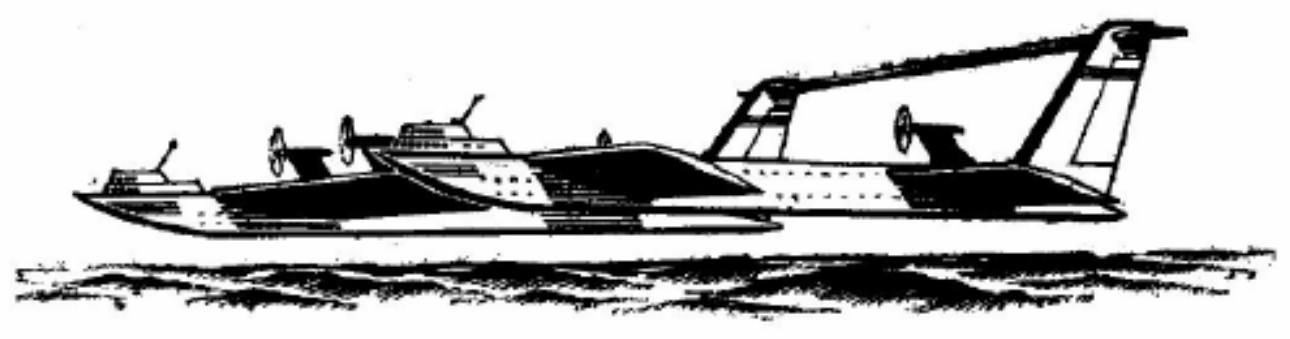

Figure 4: Ekranoplan Large Weilandcraft developed by Weiland [6] 
These planes were designed in the 1960s for a multitude of purposes, including military and commercial applications. During this time, the Soviet Union became a leader in the ekranoplan field developing a wide range of concepts for everyday use. Many of their concept designs can be seen in Figure 5. Popular design features included elevated tail mounts and power augmented ram units. As a result of their efforts, the natural pitch instability issues were addressed through tail placement and special profiling of the wing sections. [2]
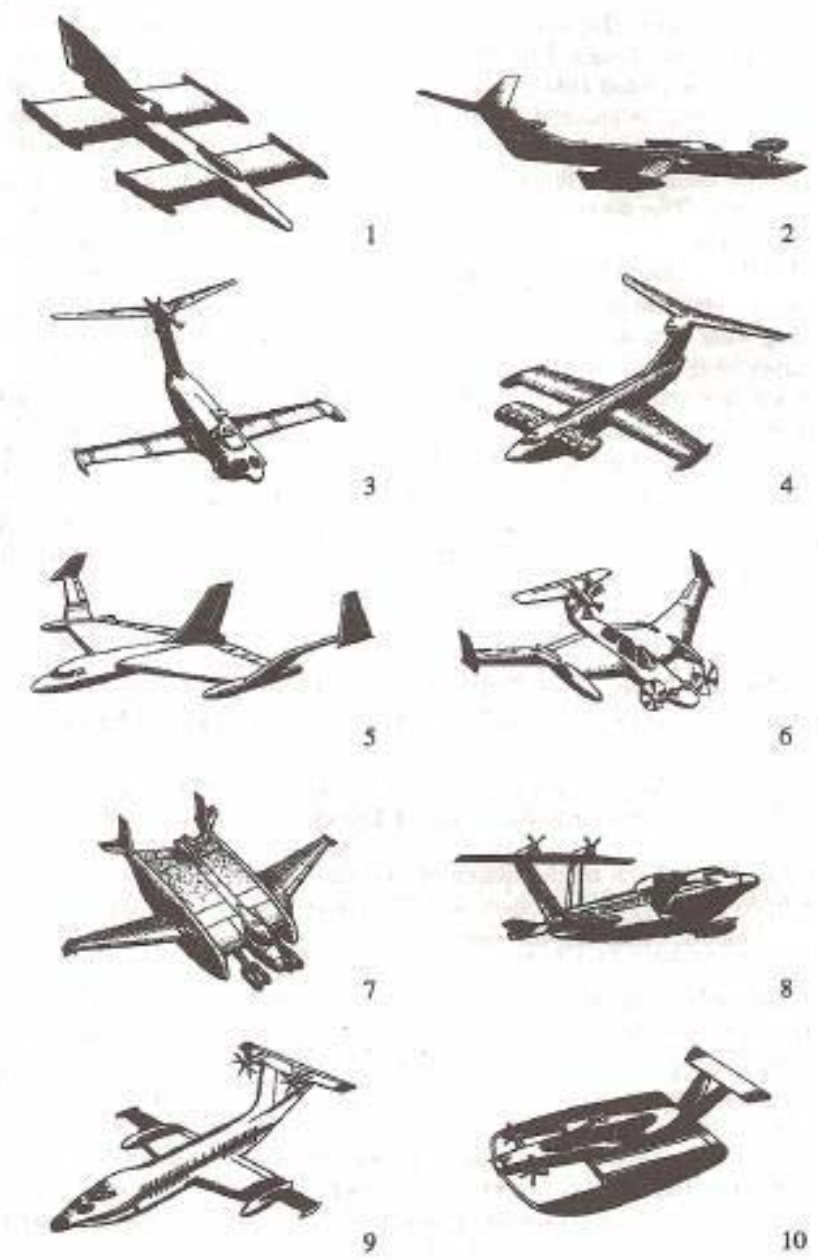

Figure 5: Collection of Russian Ekranoplan Designs [2] 
Shortly after the end of the Cold War, development in this field waned until recently with the design of the Boeing "Pelican” by Phantom Works, as seen in Figure 6.

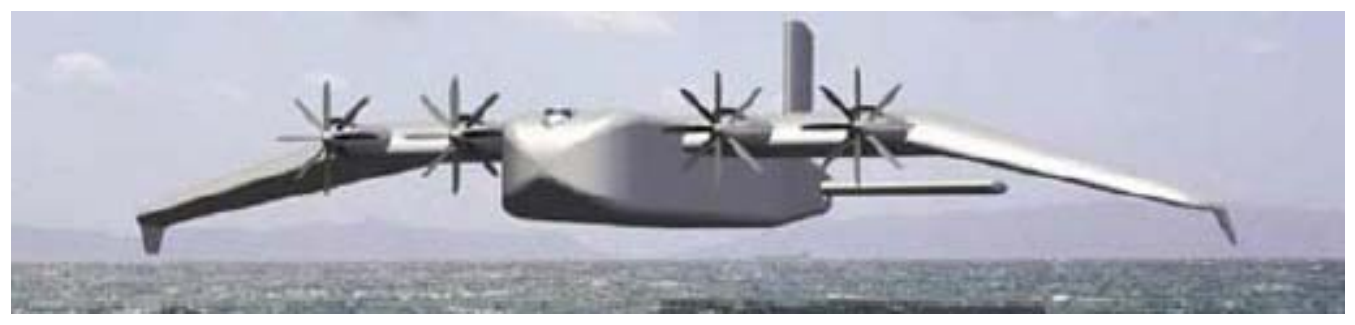

Figure 6: Boeing Pelican by Phantom Works [7]

This aircraft is twice the size of the world's largest current aircraft and would operate as a long range, transoceanic transport, flying within $20 \mathrm{ft}$ of the water's surface. [7]

\subsection{Numerical Wing-in-Ground-Effect Research}

In the early years of aircraft development, low speed models were predominately used to predict aerodynamic forces for flight. In order to simplify calculations, these classical problems were assumed to have flow that was inviscid, incompressible, and irrotational.

In 1922, Dr. C. Wieselsberger pioneered research into ground effect when he placed an image of a lifting surface below the ground plane. Approximately ten years later, Tomotika used conformal mapping to theoretically predict the flow past a flat plate in close proximity to the ground. During the 1940s the field of ground effect began moving beyond flat plates and into more complex geometries, including circular-arc and Joukowski airfoils. It was not until the 1980s when the concept of extreme ground effect began to be explored and modeled. [8] This extreme ground effect region can be located within approximately $10 \%$ of the chord length from the ground [2]. 
In recent years, vast improvements have been made in modeling techniques which allow for more extensive geometries to be studied. This includes zero thickness surfaces similar to those found in the automotive industry and three-dimensional airfoils which provide a more realistic representation of the flow in ground effect. [8]

\subsection{Experimental Wing-in-Ground-Effect Research}

In the early 1930s the ability of researchers to perform ground effect testing with efficient and accurate methods was very limited. The primary method for testing ground effect was through the use of a fixed ground board placed underneath the model which was intended to simulate a near ground experience. This method is still in use today, though not as accurate as mirror-image or moving ground plane modeling. However, through early experimental testing it was found that the ground effect phenomenon exhibits itself at distances from the ground less than the chord length of the wing, but the most advantageous range of ground clearances normally lies below $25 \%$ of the chord [2].

During the mid 1970s, amidst the tension of the Cold War, research into ram-lift for par-wing aircraft became highly popular. A par-wing vehicle, as seen in Figure 7, is similar to a wing-in-ground (wig) vehicle but with the addition of a power plant located on the nose that provides additional lift under the wing. This makes it possible to take-off with zero to little forward speed [9]. Ailor and Eberle experimented with determining the lift and pressure distribution that would accompany this type of lift, using a multitude of geometries. They were able to determine through both $2 \mathrm{D}$ and $3 \mathrm{D}$ testing that some geometries are capable of generating significant lift during ground effect [10]. 


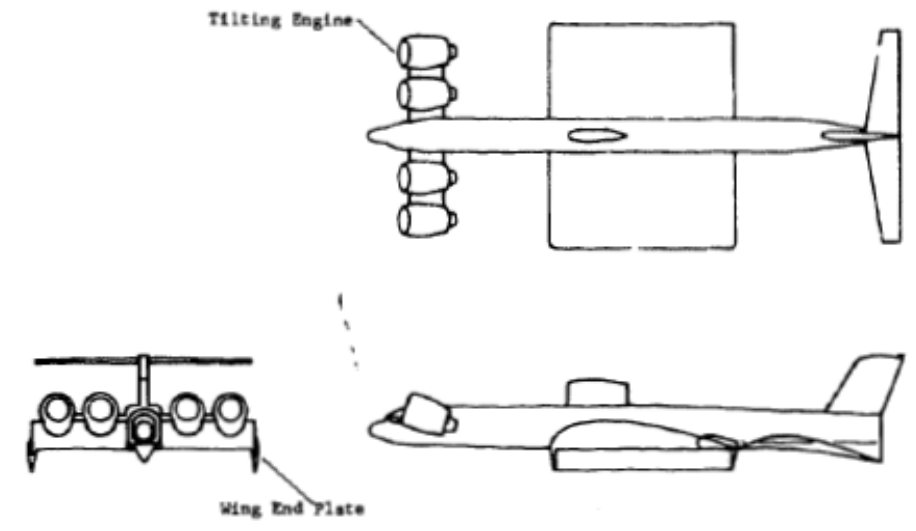

Figure 7: PAR-Wing Vehicle [9]

Later, in the 1990s, research was renewed on par-wing technology for the use in a launcher capable of assisting in horizontal take-off space flight. As part of this research a more complex model was used, the NACA 4415 airfoil shown in Figure 8, with varying parameters such as angle of attack, flap angle, height from ground, and the use of end plates. Through fixed board testing, it was found that both the lift and drag coefficients increased with proximity to the ground plane. [11]

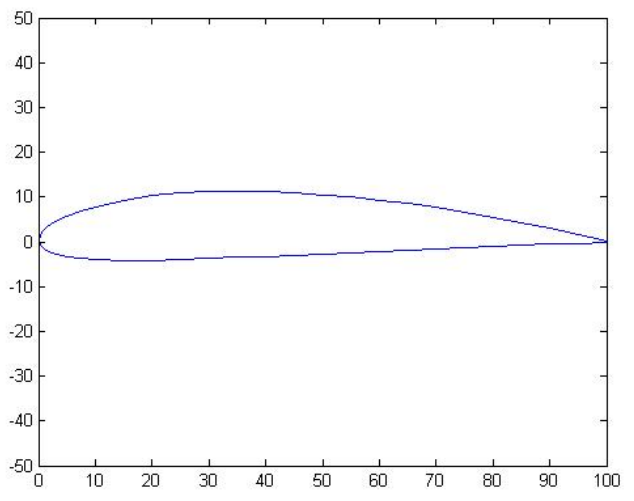

Figure 8: NACA 4415 Airfoil [12] 
In 1996, research was performed on a NACA 4412 airfoil, shown in Figure 9, to explore the occurrence of force reduction as ground clearance decreases. This technology is of particular interest to the racecar industry. Using ground board testing with an angle of attack of zero and comparing the results to previous research and computational work, it was found that the force reversal phenomena is a result of merging boundary layers as the ground plane approaches. In addition, this phenomenon seems to occur at higher ground locations for cambered airfoils and other high lift devices than for symmetric airfoils. [13]

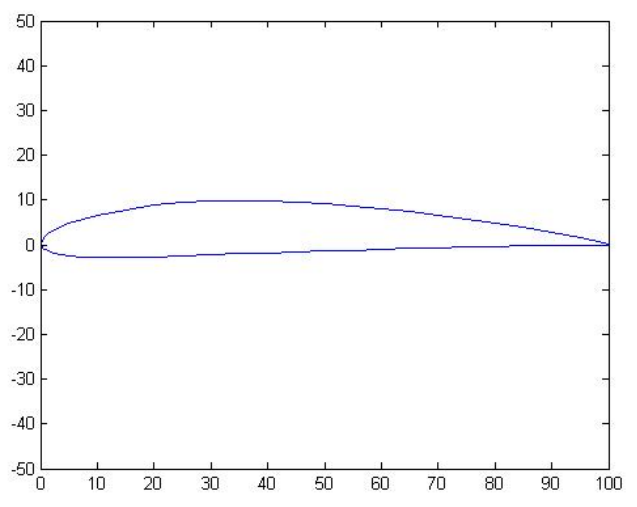

Figure 9: NACA 4412 Airfoil [12]

The most recent studies were performed in 2007 by Ahmed, Takasaki, and Kohama using moving ground testing on a NACA 4412 airfoil. During this experiment, the angles of attack and ground clearances were varied to determine their impact on the aerodynamic characteristics. They found that in extreme ground effect, a significant drop in lift force was exhibited though in normal ground effect the lift forces increase as the ground approaches. In addition, the drag force increases closer to the ground for all angles of attack. [14] 


\subsection{Computational Wing-in-Ground-Effect Research}

Computational modeling has only begun to be applied to ground effect research in the past fifteen years. Research began around the early 1990s when Steinback and Jacob produced high Reynolds number data for airfoils in ground effect. The main objective of this research was to determine the viscous effects as the ground plane was approached.

In 1996, Hsiun and Chen began research into the effect of Reynolds number on the aerodynamic characteristics of a NACA 4412 airfoil during ground effect. Their models were simulated in a turbulent regime with a SIMPLE, k-epsilon solver. From these simulations, it was found that both the lift coefficient and the lift-to-drag ratios increase with Reynolds number. In addition, the pressure distribution on the leading edge is more strongly influenced at lower Reynolds numbers. It was also noticed that with a decrease in the ground clearance, the lift coefficients increase [15]. This is consistent with the results found by Chawla, Edwards, and Franke's on a similar airfoil in wind tunnel testing. [11]

In the late 1990s, questions arose about the validity of computational and experimental testing that uses fixed ground plane methods, implying that for accurate results, the ground plane must be in motion. There are four types of possible modeling techniques: mirror-image, slip condition, stationary ground, and moving ground. The most accurate of these techniques being the moving ground in which a ground plane, usually simulated with a rotating belt, moves at the same speed as the air flow generated with a fan. This technique is representative of a body moving over the ground with no additional wind other than that caused by the motion of the body through the environment. [16] 
In 2003, Chun and Chang clarified the 2D ground effect characteristics for both the moving and fixed ground boundary layers in turbulent flow using the NACA 4412 airfoil. The results indicated that the change in lift and moment between the two techniques was minimal but drag was smaller for the fixed plane than for the moving plane. [17]

\subsection{Pitch Stability Research}

Since the beginning of aircraft development, it has been apparent that longitudinal stability is vitally important to the success of controlled flight. Various methods have been used in order to correct the natural instabilities as the angles of attack vary. Much of the previous research was focused in the area of supersonic flight, specifically for use with missiles. There are two main methods for stabilizing the pitch on missiles. The first is with the use of nose mounted canards and nose flaps which can prove to be very stable at higher Mach numbers [18]. The second method utilizes the location of the fins that extend from body slots to affect the longitudinal stability. This is effective only at angles of attack higher than 15 degrees [19].

While pitch stability has been studied in relation to the proximity of the ground, solutions to resolve the aerodynamic instabilities have not been evaluated without taking the aircraft out of ground effect. A design by De Divitiis, shown in Figure 10, incorporated a high positioned tail into a ground effect aircraft. This high tail, located outside of the ground effect regime, would effectively restore the aerodynamic moment [20]. 


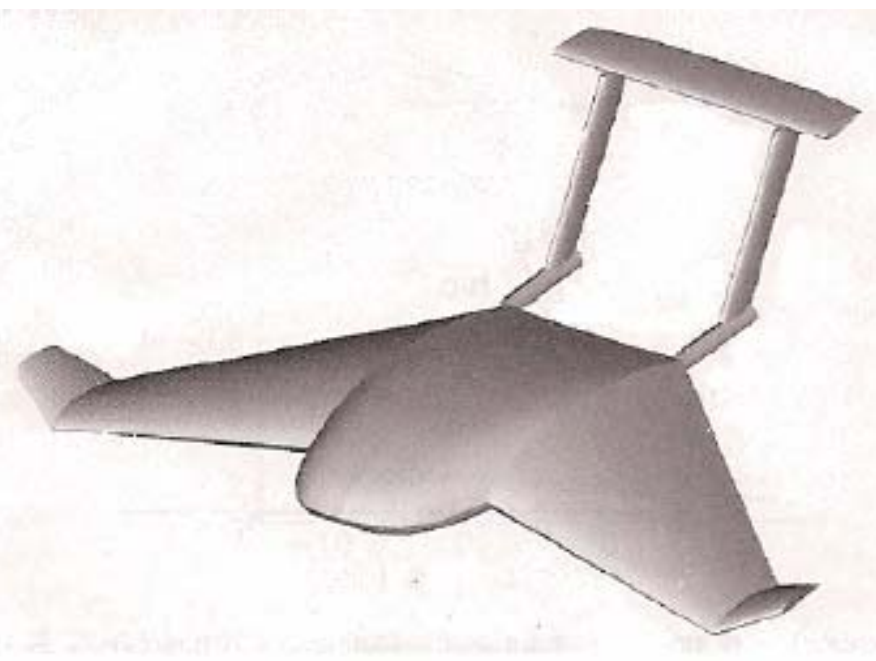

Figure 10: Concept design by De Divitiis [20]

\subsection{Previous AirRay Research}

For the initial research on AirRay, the Wortmann FX 63-137 airfoil, seen in

Figure 11, was chosen due to the availability of low speed wind tunnel data and the reasonably high lift coefficients at varying angles of attack.

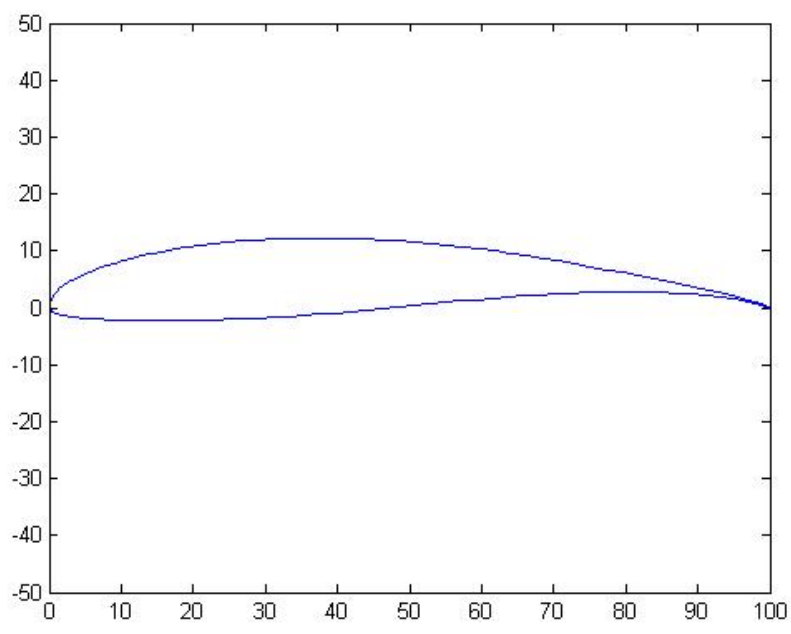

Figure 11: Wortmann FX 63-137 [21] 
The aerodynamic data of the Wortmann airfoil can be found in Figure 12. This particular airfoil is commonly used on sailplanes which have similar flight objectives to ground effect vehicles.

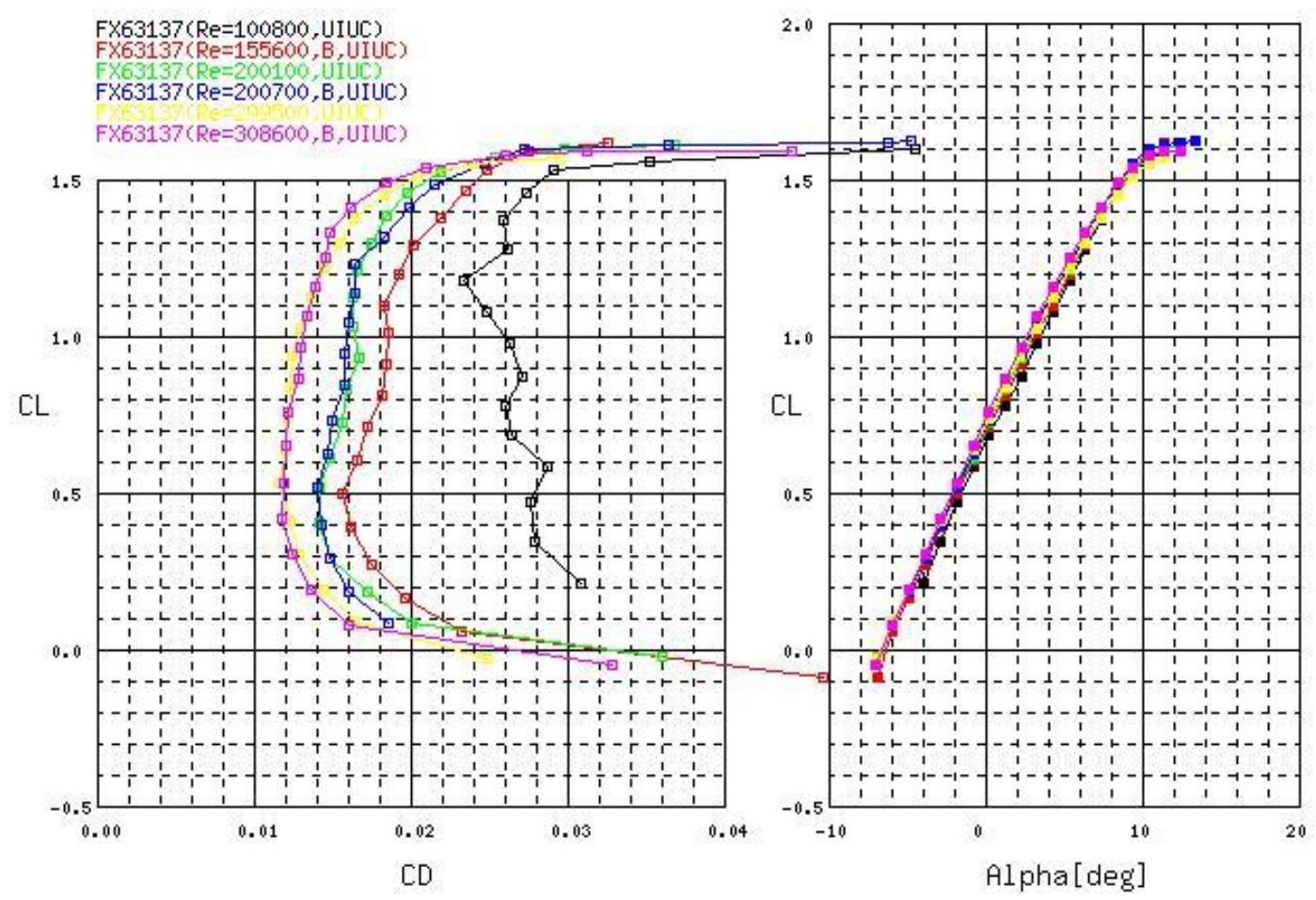

Figure 12: Wortmann FX 63-137 Aerodynamic Data [21]

Computational analysis has been performed on the Wortmann FX 63-137 to determine the extent of lift enhancement during ground effect as well as the change in the center-of-pressure locations at varying angles of attack. The lift was found to increase $30 \%$ over that experienced by a moving body not located in the ground effect regime. The center-of-pressure was found to have traveled a maximum of $16 \%$ of the chord length [22]. These results were found through analyzing a series of CFD simulations 
which were validated by comparison to a known flat plate airfoil in ground effect. These results were found for a series of angle-of-attacks and height-to-chord ratios.

Similar to previous theoretical research, the lift on the airfoil was found to increase as proximity to the ground increased. In addition, the drag forces were reduced as the airfoil approached the ground. The center-of-pressure was found to maintain a nominal travel distance as long as the angle of attack remained constant. [22] However, with a changing angle of attack, the travel of the center-of-pressure can become significant.

\subsection{Venturi Effect}

The Venturi is a tunnel or nozzle-like geometry that causes a fluid speed to increase as an effect of the fluid being forced through a narrow or constricted area. The increased speed results in a reduction of pressure [23]. An example of a Venturi can be seen in Figure 13 on a ground effect car.

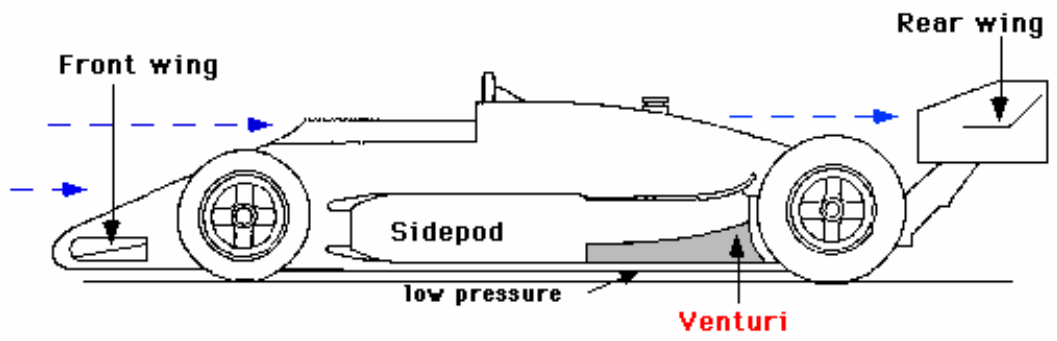

Figure 13: Venturi on Ground Effect Car [23]

In the case of the ground effect car, the front and rear wings create downforce which pushes the car to the track. The underbody venture tunnel creates a low pressure area between the chassis and the ground which sucks the car to the track. [23] 


\section{Chapter 3.0 Evaluation of Grid Setup}

This chapter discusses the initial setup and generation of the two-dimensional NACA FX 63-137 airfoils, both modified and baseline. In addition, it discusses the simulation setup and grid independence check. The adapted models include slots placed at three locations, $15 \%, 20 \%$, and $25 \%$ of the chord length. Also, these slots are placed at three angles from the vertical plane, 20, 30 and 40 degrees. The airfoils will be simulated at three velocities which represent the normal and maximum operating speeds of AirRay as well as the maximum design speed of the next generation glider.

\subsection{Grid Setup of Airfoil}

The two-dimensional figures for the NACA FX 63-137 airfoil were setup and meshed in the CAD software Gambit 2.3.16. This software was chosen because it directly interfaces with the CFD software, Fluent 6.2.16. For this analysis, two main types of geometries were created, the baseline model, which simulated a scaled, unmodified FX 63-137 airfoil and a modified model which incorporated the varying slot concepts. The baseline model for an angle of attack of zero is shown in Figure 14. An example of a slotted model at 10 degrees angle of attack is shown in Figure 15. 


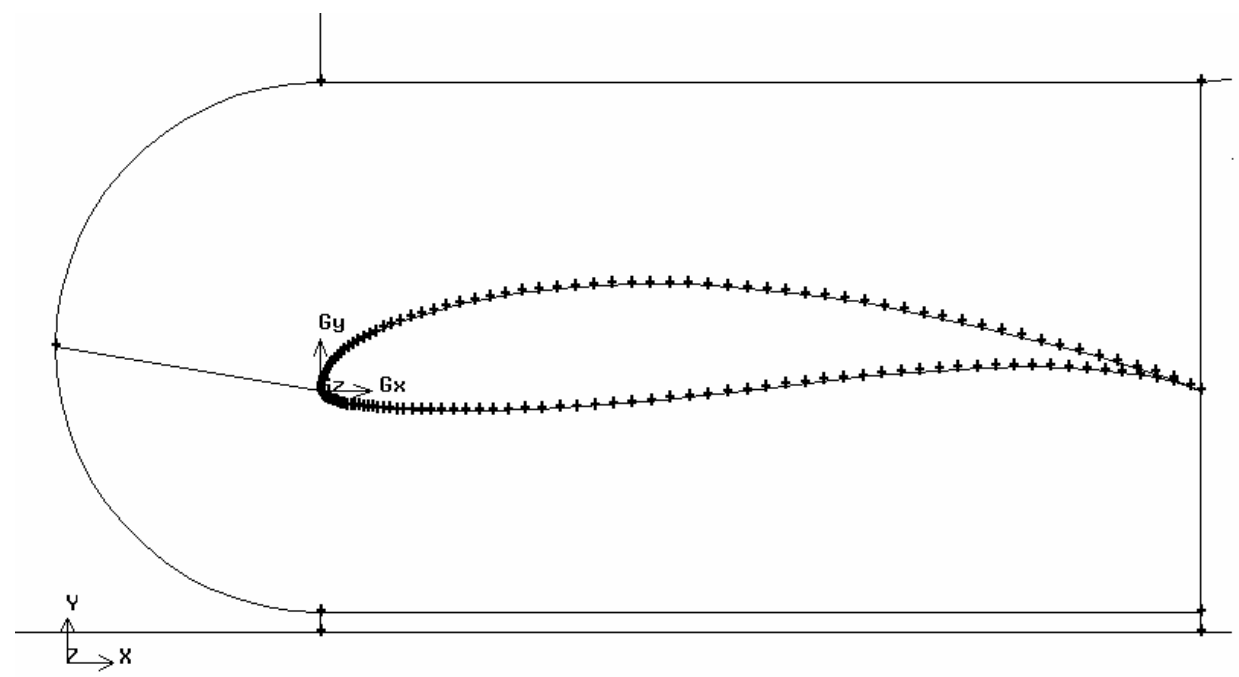

Figure 14: Wortmann FX 63-137 Baseline Model

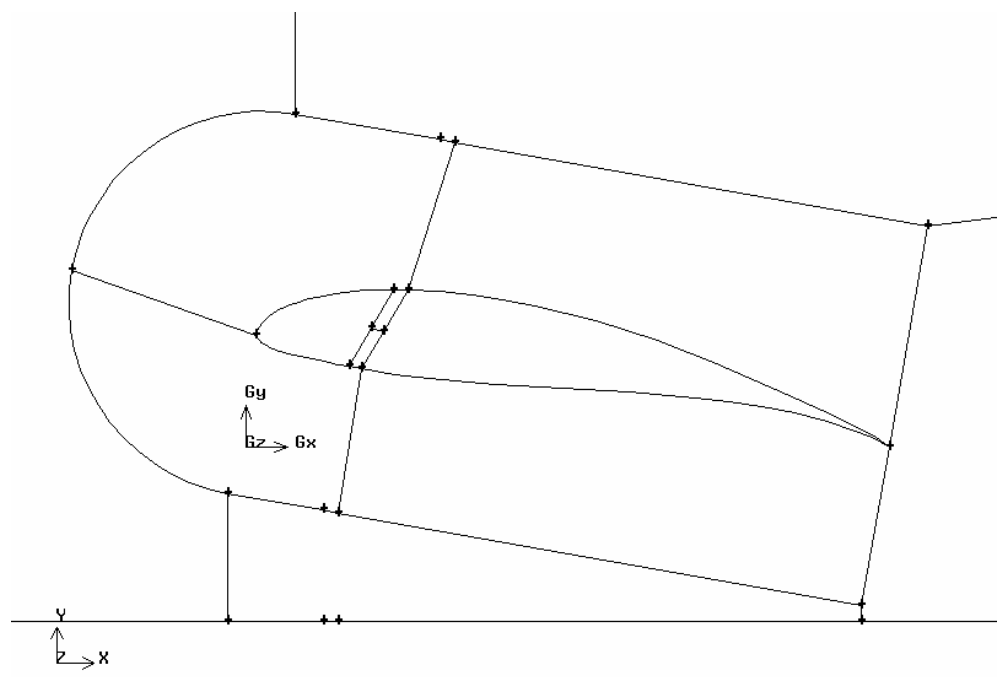

Figure 15: Wortmann FX 63-137 Slotted Model

Each model was scaled from the full version to have a chord length of one meter in order to simplify the modeling process and Reynolds number calculations. In addition both types of models were placed at $25 \%$ of the chord length above the ground from the 
lowest point on the airfoil. This location was chosen because it is within the most advantageous range of ground clearances for optimal ground effect [2].

The grid of the airfoil was constructed with a structured mesh concentrating nodes at the leading and trailing edge, for the baseline, and for the modified airfoil, also around the slot entrance and exit. A close-up view of the slotted airfoil is shown in Figure 16 which shows the enhanced mesh immediately surrounding the airfoil and the concentration of cells within the slot.

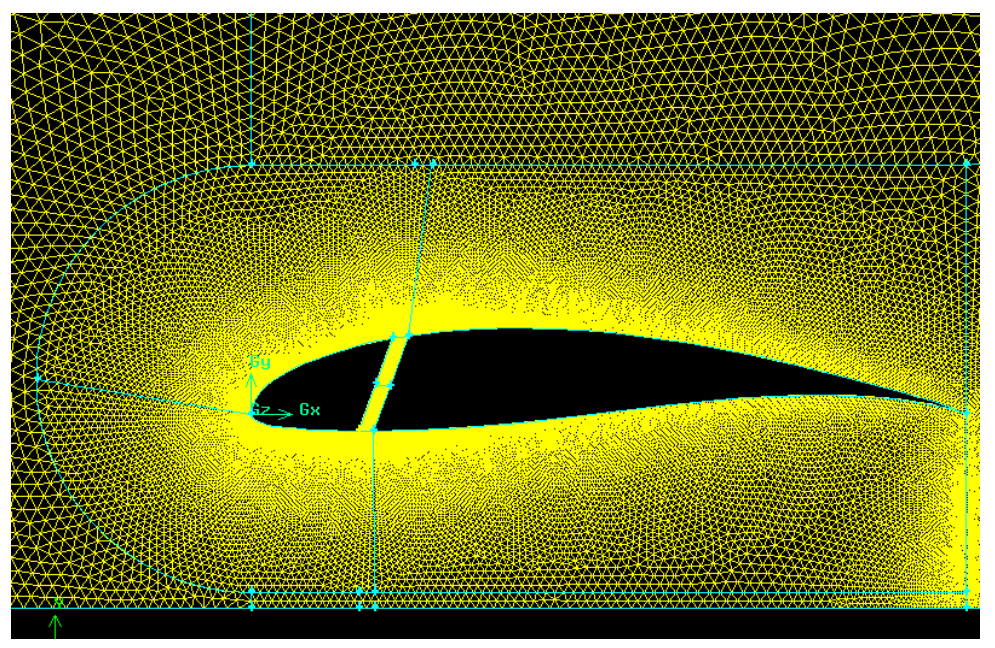

Figure 16: Close-up of Slotted Model with Mesh

Once the structured meshes were generated, they were used to create unstructured triangular cells which grew at a rate of 1.05 away from the airfoil as shown in Figure 17. The specific meshes are consistent for all the slotted airfoils with a similar mesh being created for the baseline except without the focus on the slot. 


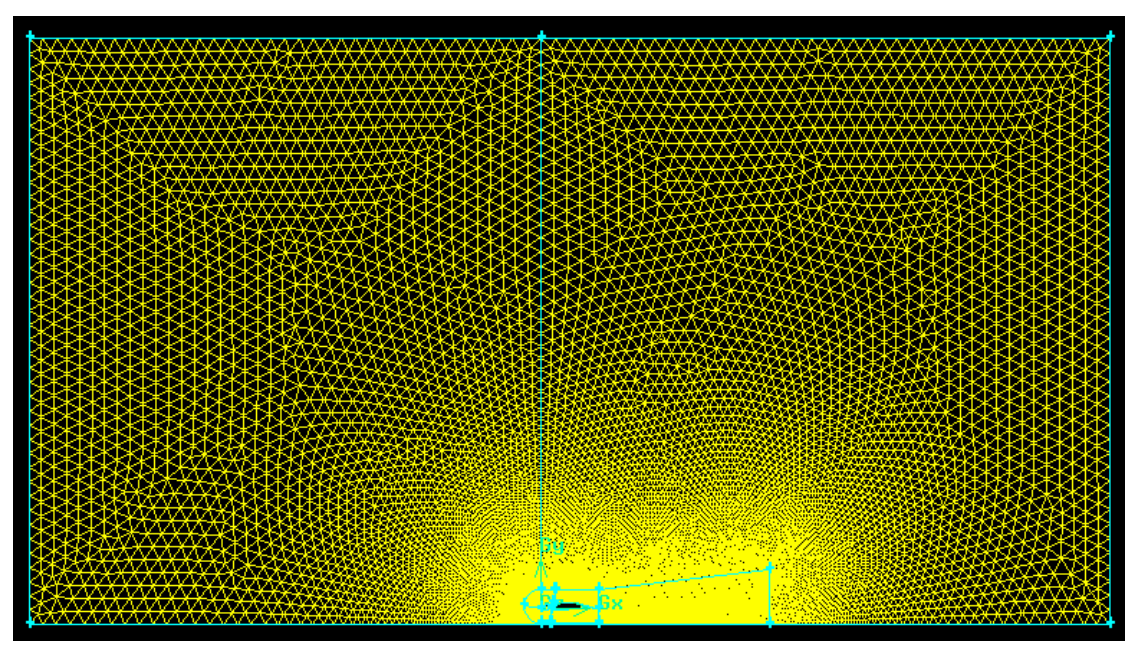

Figure 17: Wortmann FX 63-137 Slotted Model with Mesh

The maximum that the cells were allowed to grow to were 0.3 for the area acting as a boundary immediately around the airfoil and 0.25 for outside of the airfoil boundary and plume area.

To imitate real flow, a velocity inlet was placed nine chord lengths upstream with a pressure outlet located an equal distance downstream. In addition, a stationary wall was placed ten chord lengths above the airfoil, where it acts as a boundary to the simulation but does not restrict the movement of the flow, as well as a stationary wall a quarter chord beneath the airfoil. For positive angles of attack the trailing edge was used as the point of rotation whereas for negative angles of attack the leading edge was used. This designation is to maintain the quarter chord distance from the ground plane. After generation, the baseline model had approximately 60,000 nodes and the slotted models had approximately 85,000. 


\subsection{Computational Setup of Airfoil}

For the computational fluid dynamics analysis, Fluent 6.2.16 was chosen because of its ability to model two-dimensional flow and interface with the Gambit software. Within Fluent the stationary ground wall can be changed to a moving wall which will most accurately reflect the moving ground plane of the actual environment. Both the moving ground plane and the velocity inlet are set to the same velocity during simulation to mimic ground effect without the addition of environmental effects.

Since the airfoil has been scaled to a chord length of 1 meter from the original 8 foot mean chord, the associated wind speeds will also have to be scaled. For the prototype, the velocities of 12 and $18 \mathrm{~m} / \mathrm{s}$ are encountered during flight and for the commercial craft, a maximum design velocity of $28 \mathrm{~m} / \mathrm{s}$. The scaled model will therefore encounter speeds of approximately 7.5, 11.5 and $18 \mathrm{~m} / \mathrm{s}$. This is found through relating the chord length and velocity through the Froude equation found in Equation [1]. The Froude number is non-dimensional group which is used for flow with the free surface.

$$
F r=\frac{V}{\sqrt{g l}}
$$

In order to determine the type of flow around the airfoil, the Reynolds number was calculated using Equation [2]. The density was taken at sea level to be $1.225 \mathrm{~kg} / \mathrm{m}^{3}$ with a viscosity of $1.789 \times 10^{5} \mathrm{~kg} / \mathrm{m}-\mathrm{s}$.

$$
\operatorname{Re}=\frac{\rho V L}{\mu}
$$

At $18 \mathrm{~m} / \mathrm{s}$ the Reynolds number was calculated to be $1.9 \times 10^{6}$, which indicates turbulent flow. Turbulent flow occurs at Reynolds numbers of $1.5 \times 10^{6}$ and higher [24]. The 
Reynolds number at $11.5 \mathrm{~m} / \mathrm{s}$ was determined to be $7.9 \times 10^{5}$, which indicates transitional flow. This region is indicated by Reynolds numbers larger than $3 \times 10^{5}$ and less than $1.5 \times 10^{6}$ [24]. At $7.5 \mathrm{~m} / \mathrm{s}$ the Reynolds number was calculated to be $5.2 \times 10^{5}$, which also falls within the transient region. For the slotted models, there is an acceleration of velocity within the slot itself which can trigger turbulent flow, therefore even with the transient region indicated in the $7.5 \mathrm{~m} / \mathrm{s}$ flow, all models will be simulated with turbulent flows.

For the calculations, a two-dimensional double precision simulation with a k-epsilon solver was used. The double precision will more accurately predict the flow field, while the k-epsilon solver is robust and reasonably accurate for a wide range of turbulent flows [25]. The additional Fluent solver settings are shown in Table 1.

Table 1: Fluent Settings

\begin{tabular}{|c|c|}
\hline Pressure Solver & Presto! \\
\hline Momentum Equation Solver & First Order Upwind Discretization \\
\hline Energy Equation Solver & First Order Upwind Discretization \\
\hline Turbulent Kinetic Energy Solver & First Order Upwind Discretization \\
\hline Turbulent Dissipation Rate & First Order Upwind Discretization \\
\hline
\end{tabular}

The first order upwind discretizations were used in the solvers to assist in convergence of the flow. The Presto! solver is useful in that it improves accuracy with surfaces that are strongly curved. In order to accommodate for the increased pressurization at the walls as a result of the nearness of the airfoil due to the clearance necessary for ground effect, a non-equilibrium wall treatment was applied. This particular treatment is useful for complex flows involving separation, reattachment and impingement [24]. 
There were two types of convergence criteria used for determining the solutions to the simulations. The first type of convergence checked the continuity, x-velocity, $y$ velocity, energy, $\mathrm{k}$, and epsilon residuals for a convergence of at least $1 \times 10^{-3}$. At this point, values were recorded for the forces and aerodynamics coefficients to comparatively analyze optimal performance with respect to one another in order to reduce the number of test cases. Once the optimal test cases were selected, the previous

residuals were reassessed for a convergence of $1 \times 10^{-5}$ in addition to the convergence of the residuals of the lift and drag coefficients.

\subsection{Validation of Fluent Results}

An initial grid of 82,000 nodes and 165,000 cells was generated for each airfoil in Gambit. This resulted from approximately 2000 grid points located on the surface of the airfoil. The generated surrounding triangular mesh contained reasonably negligible amounts of skewed cells and was assumed to be significantly fine for the initial grid independence check. Two types of adaptation were attempted in order to compare simulation time and productivity of modeling.

The first technique used Gambit to increase the number of nodes on the model to an amount one order higher than the original. This lead to 480,000 nodes on the baseline model once the adaptation took place. The model was simulated with an $18 \mathrm{~m} / \mathrm{s}$ flow which required 36 hours to converge.

The second technique used the adapt tool in Fluent to make modifications to the existing mesh. Both boundary and region adaptations were used to increase the size of the mesh. These tools were used to refine the grid until a factor of at least 1.3 was achieved [26]. Boundary adaptation is primarily used to refine cells located within a certain 
number of cells of the boundary zones [25]. In this case, within one cell of the selected zones was used. The secondary type of adaptation used was the region function. It focuses on user selected areas of the mesh to improve meshes that grow as the distance increases from the boundaries [25]. In this case, the entire mesh area was selected for improvement. The ensuing simulation time for this technique was approximately two hours. The results from the simulation of these two techniques can be seen in Table 2, where the primary characteristic used for comparison was the center-of-pressure location.

Table 2: Grid Independence Check

\begin{tabular}{|l|c|c|c|c|c|c|c|c|}
\hline & $\mathrm{AOA}$ & $\mathrm{Fx}$ & $\mathrm{Fy}$ & $\mathrm{Xcp}$ & $\mathrm{Cd}$ & $\mathrm{Cl}$ & $\mathrm{M}(0,0)$ & Nodes \\
\hline Normal & 5 & 30.936 & 152.077 & 0.589 & 0.156 & 0.766 & 89.391 & 82000 \\
\hline Gambit Adaption & 5 & 58.958 & 182.767 & 0.602 & 0.297 & 0.921 & 109.685 & 480000 \\
\hline Fluent Adaption 1 & 5 & 38.435 & 127.834 & 0.627 & 0.194 & 0.644 & 79.382 & 330000 \\
\hline Fluent Adaption 2 & 5 & 33.529 & 120.856 & 0.623 & 0.169 & 0.609 & 76.179 & 365000 \\
\hline \%Diff (Normal - Adaptive 1) & & 19.510 & 18.965 & 6.061 & & & & \\
\hline \%Diff (Adaptive 1 - Adaptive 2) & & 14.633 & 5.774 & 0.727 & & & & \\
\hline
\end{tabular}

Considering the simulation time required for each technique, the adaptation method provided by Fluent was used to verify grid independence. The first adaptation of the original mesh used both the boundary and then region functions just once. The difference between the center-of-pressure positions was approximately $6 \%$. Therefore the adaptation was repeated again, but with each function being used twice alternately. This resulted in a value for the center-of-pressure position being less than $1 \%$ away from the previous adaptation method results. The numerical uncertainty in a fine-grid solution is at a maximum of 2.2\% [26]. This indicates that the first adaptation method was grid independent. 


\section{Chapter 4.0 Results}

The study conducted on the Wortmann FX 63-137 focused primarily on evaluating the effect of different geometric slots on limiting the travel of the center-ofpressure. This is of such significance because the stability of the center-of-pressure allows for the glider to be able to maintain steady flight. If the travel of the center-ofpressure does not remain restricted, AirRay could move in and out of ground effect and either lose the aerodynamic influence of the ground or accidentally impact with the ground plane.

\subsection{Analysis of Initial Convergence Data}

In order for any comparison to be made, the original Wortmann FX 63-137 airfoil was simulated with the initial convergence criteria to determine the range that the centerof-pressure traveled. Figure 18 shows the maximum travel that occurred over a range of angle of attacks, at each velocity, as a percentage of the chord length.

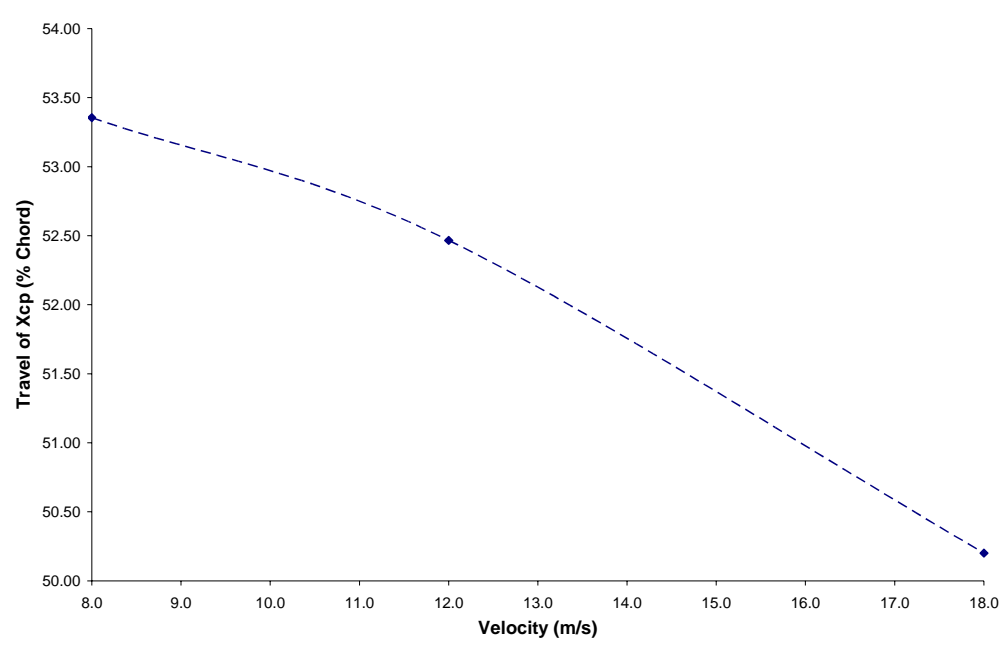

Figure 18: Max Travel of Baseline Xcp across AOA as \% of Chord 
The general trend that appears is the tendency for the center-of-pressure to travel less as the velocity increases. This indicates that control will be required most at low speeds.

Test cases were run for the three chord and vertical angle positions. The results from the CFD simulations using the initial convergence criteria are shown in Figure 19 and include the baseline data found in Figure 18.

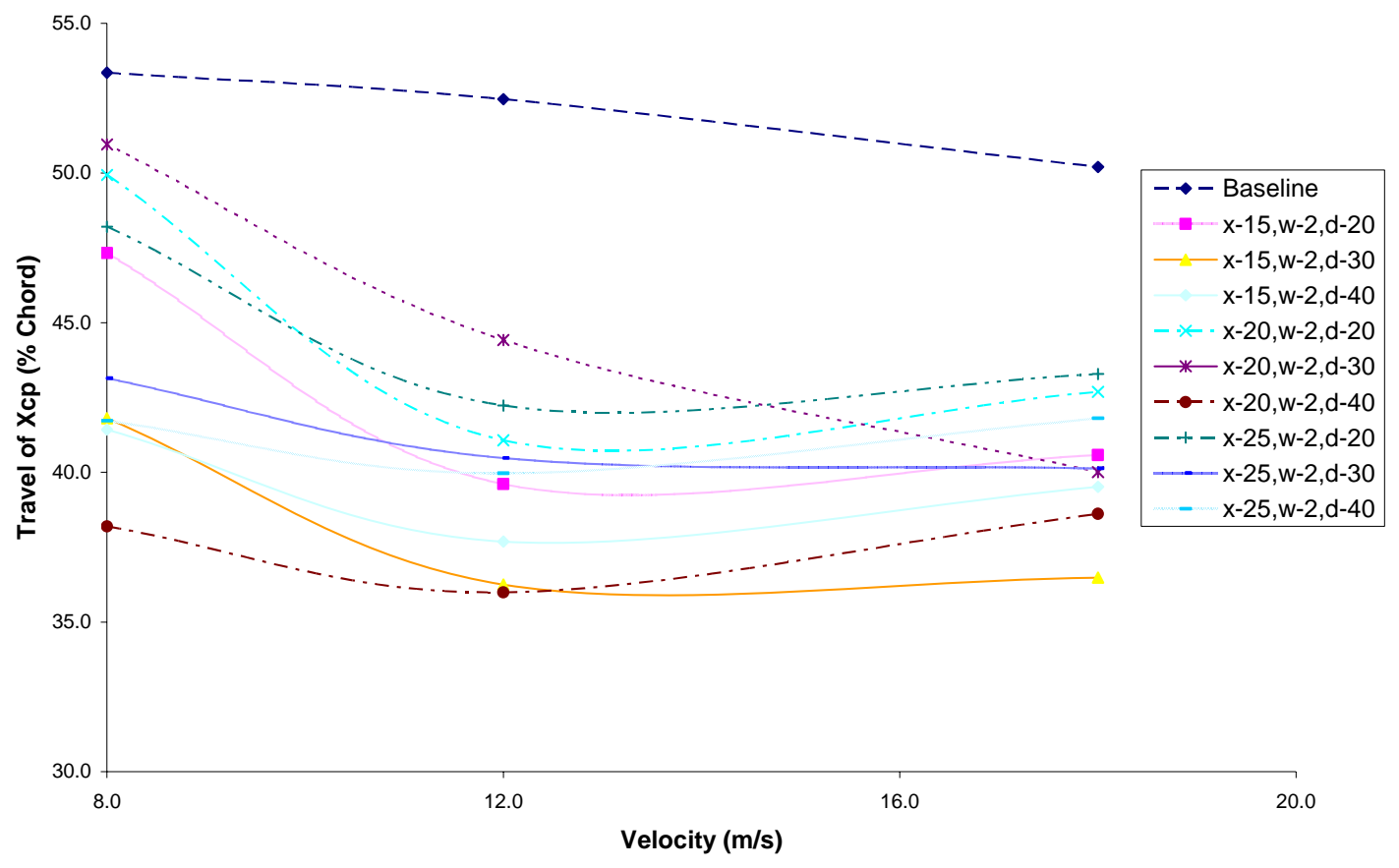

Figure 19: Average Travel of Xcp across AOA as \% of Chord

From Figure 19, two configurations appear as reducing the movement of the center-ofpressure significantly from the baseline. The $x-20, w-2, d-40$ and the $x-15, w-2, d-30$ slot geometries are located closest to the bottom of the figure, indicating the least movement as a percentage of the airfoil chord. The average travel of the center-of-pressure was calculated for each slot configuration across the three velocities and four angels of attack giving an overall average for the Xcp shift. The $\mathrm{x}-20, \mathrm{w}-2, \mathrm{~d}-40$ and the $\mathrm{x}-15, \mathrm{w}-2, \mathrm{~d}-30$ 
slot configurations were found to restrict the travel up to $40 \%$ more on average than the baseline airfoil.

The initial simulations include a negative three degree angle of attack which was included for instances in which the nose pitches down. An example of the results produced by the negative angle of attack can be seen in Figure 20. This figure shows the position of the center-of-pressure on the x-axis with zero indicating the leading edge of the airfoil and one indicating the trailing edge.

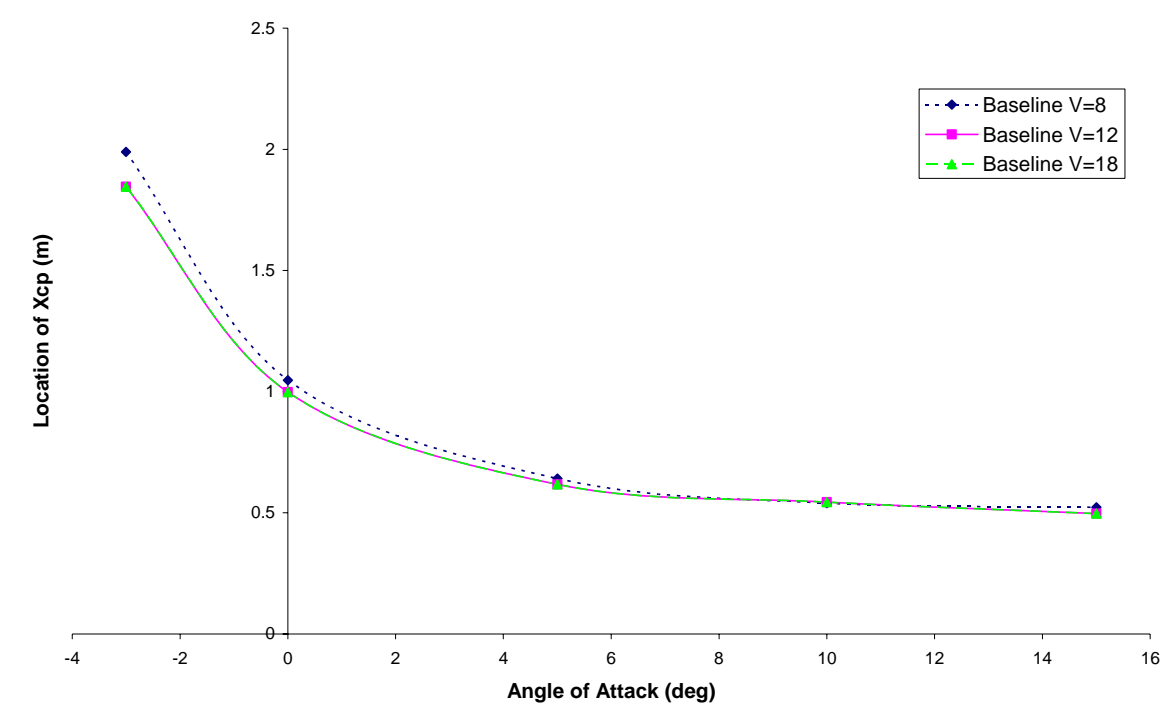

Figure 20: Baseline Travel of Xcp Along Chord Length with respect to AOA

As the angle of attack decreases, the location of the center-of-pressure begins to travel to the trailing edge of the airfoil and with a negative angle of attack, travel outside the boundaries of the body. During many of the simulation cases, the center-of-pressure location existed one and a half to two times the chord length outside the airfoil for negative angles of attack. This data can be viewed in Appendix A. The extreme shift in the center-of-pressure location for the negative angle of attack could potentially be 
explained through the Venturi effect. Due to the camber and position of the airfoil relative to the ground, a nozzle-like figure was created two-dimensionally as seen in Figure 21.

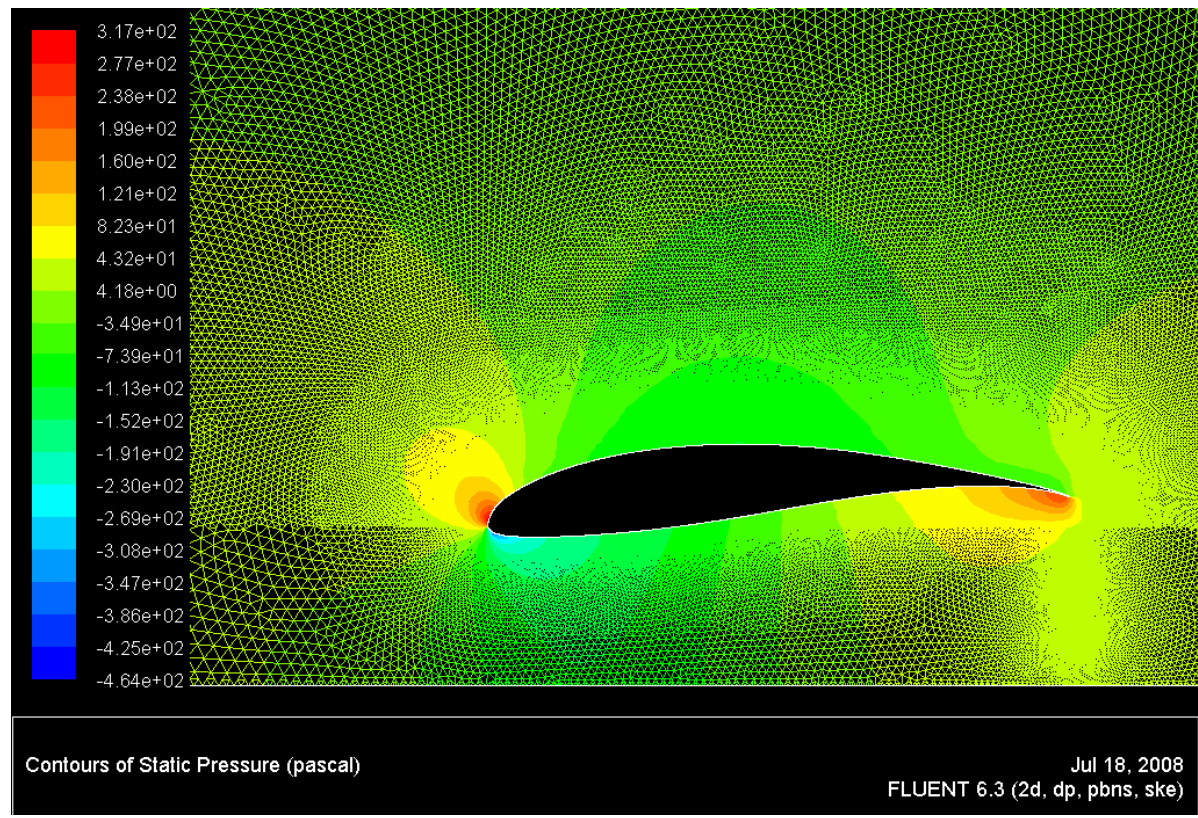

Figure 21: Static Pressure Distribution of Baseline Model at V=18 m/s

The creation of this shape resulted in a decrease in the pressure at the nose and an increase in the pressure build-up underneath the trailing edge, causing the center-ofpressure location to shift significantly beyond the tail.

The individual results for the two most beneficial slot arrangements have been placed into a series of tables which show the center-of-pressure locations at differing angles of attack and velocities. Table 3 shows the baseline data which indicates an Xсp outside of the 1 meter chord length for an angle of attack at zero. This is also a potential result of the Venturi effect. Table 3 shows the positions of the center-of-pressures for the three velocities as a function of angle of attack. The "\% Travel” indicates the range that the Xcp traveled as a percentage of the chord length as both a function of the angle of 
attack and velocity. From Table 3 the average of the travel of the center-of-pressure across all velocities and angles of attack was determined to be $52.0 \%$.

Table 3: Baseline Center-of-Pressure Data

\begin{tabular}{|c|c|c|c|c|}
\hline $\mathrm{AOA}(\mathrm{deg})$ & $\mathrm{Xcp}(\mathrm{V}=8)$ & $\mathrm{Xcp}(\mathrm{V}=12)$ & $\mathrm{Xcp}(\mathrm{V}=18)$ & \% Travel \\
\hline 0.0 & 1.08 & 1.05 & 0.999 & 1.04 \\
\hline 5.0 & 0.671 & 0.641 & 0.617 & 0.643 \\
\hline 10.0 & 0.592 & 0.539 & 0.544 & 0.558 \\
\hline 15.0 & 0.545 & 0.522 & 0.497 & 0.521 \\
\hline \% Travel & 53.4 & 52.5 & 50.2 & 52.0 \\
\hline
\end{tabular}

Table 4 shows the $\mathrm{x}-15, \mathrm{w}-2$, d-30 slotted airfoil data, which was one of two slot configurations that appeared to limit the center-of-pressure travel more effectively than other models. The average travel of the center-of-pressure over all the angle of attacks and velocities was $38.2 \%$ which is an approximate $27 \%$ decrease in the travel from the baseline model.

Table 4: x-15, w-2, d-30 Center-of-Pressure Data

\begin{tabular}{|c|c|c|c|c|}
\hline $\mathrm{AOA}(\mathrm{deg})$ & $\mathrm{Xcp}(\mathrm{V}=8)$ & $\mathrm{Xcp}(\mathrm{V}=12)$ & $\mathrm{Xcp}(\mathrm{V}=18)$ & \% Travel \\
\hline 0.0 & 0.953 & 0.891 & 0.880 & 0.908 \\
\hline 5.0 & 0.724 & 0.700 & 0.659 & 0.626 \\
\hline 10.0 & 0.560 & 0.557 & 0.547 & 0.555 \\
\hline 15.0 & 0.535 & 0.528 & 0.515 & 0.526 \\
\hline \% Travel & 41.8 & 39.7 & 36.5 & 38.2 \\
\hline
\end{tabular}

Table 5 shows the data for the $\mathrm{x}-20, \mathrm{w}-2$, d-40 slotted airfoil. This airfoil showed slight improvement in the average travel of the center-of-pressure over the $x-15, w-2, d-30$ airfoil with an average travel of $37.5 \%$ compared to the $38.2 \%$ mentioned previously.

Table 5: x-20, w-2, d-40 Center-of-Pressure Data

\begin{tabular}{|c|c|c|c|c|}
\hline AOA (deg) & $\mathrm{Xcp}(\mathrm{V}=8)$ & $\mathrm{Xcp}(\mathrm{V}=12)$ & $\mathrm{Xcp}(\mathrm{V}=18)$ & \% Travel \\
\hline 0.0 & 0.904 & 0.881 & 0.899 & 0.894 \\
\hline 5.0 & 0.618 & 0.618 & 0.616 & 0.617 \\
\hline 10.0 & 0.546 & 0.544 & 0.537 & 0.542 \\
\hline 15.0 & 0.522 & 0.521 & 0.512 & 0.518 \\
\hline \% Travel & 38.2 & 36.0 & 38.6 & 37.6 \\
\hline
\end{tabular}


While the $18 \mathrm{~m} / \mathrm{s}$ velocity was shown to have less travel with the $15 \%$ chord position, the 20\% chord adequately compensated for the center-of-pressure travel at lower velocities. Therefore, the $\mathrm{x}-20, \mathrm{w}-2, \mathrm{~d}-40$ was examined further with the initial convergence criteria to estimate whether its configuration would achieve the best possible stability for the slotted style of pitch control.

Since the chord position was a midrange value but the vertical slant was a maximum value, the slant of the slot would have to be increased by 10 degrees to check whether the pitch stability improved. This would confirm whether the $\mathrm{x}-20, \mathrm{w}-2, \mathrm{~d}-40$ was an improved configuration out of these test cases. Table 6 shows the resulting data from the $d=50$ simulation.

Table 6: x-20, w-2, d-50 Center-of-Pressure Data

\begin{tabular}{|c|c|c|c|c|}
\hline AOA (deg) & $\mathrm{Xcp}(\mathrm{V}=8)$ & $\mathrm{Xcp}(\mathrm{V}=12)$ & $\mathrm{Xcp}(\mathrm{V}=18)$ & $\%$ Travel \\
\hline 0.0 & 0.837 & 0.856 & 0.885 & 0.860 \\
\hline 5.0 & 0.601 & 0.605 & 0.600 & 0.602 \\
\hline 10.0 & 0.539 & 0.539 & 0.530 & 0.536 \\
\hline 15.0 & 0.516 & 0.515 & 0.504 & 0.512 \\
\hline \% Travel & 32.1 & 34.1 & 38.1 & 34.8 \\
\hline
\end{tabular}

On average, the new slot configuration was able to restrict the center-of-pressure movement by another $6 \%$ compared to the $\mathrm{x}-20, \mathrm{w}-2, \mathrm{~d}-40$ slot. At higher velocities the center-of-pressure travel begins to stabilize, however, velocities as low as the $8 \mathrm{~m} / \mathrm{s}$ still see up to $15 \%$ less shift from the 40 degree angle to the 50 degree angle. Therefore the vertical slot was increased again by 10 degrees to determine whether the center-ofpressure location would continue to travel.

Knowing that the greatest shift of the center-of-pressure will occur from the largest to smallest angle of attack, the test case was restricted to 0 degrees and 15 
degrees. The average travel of the center-of-pressure is approximately $33 \%$ of the chord which is a $5 \%$ decrease from the $d=50$ case as can be seen in Table 7 .

Table 7: x-20, w-2, d-60 Center-of-Pressure Data

\begin{tabular}{|c|c|c|c|c|}
\hline $\mathrm{AOA}(\mathrm{deg})$ & $\mathrm{Xcp}(\mathrm{V}=8)$ & $\mathrm{Xcp}(\mathrm{V}=12)$ & $\mathrm{Xcp}(\mathrm{V}=18)$ & \% Travel \\
\hline 0.0 & 0.804 & 0.835 & 0.871 & 0.836 \\
\hline 15.0 & 0.493 & 0.515 & 0.509 & 0.506 \\
\hline \% Travel & 31.1 & 31.9 & 36.2 & 33.1 \\
\hline
\end{tabular}

Using the initial convergence criteria, a trend is appearing that as the vertical angle of the slot increases, the travel of the center-of-pressure begins to stabilize at lower velocities regardless of the angle of attack. Since the control of the travel continued to improve with an increase in slant, the geometry was again altered by 10 degrees. The results of the simulation are shown in Table 8.

Table 8: x-20, w-2, d-70 Center-of-Pressure Data

\begin{tabular}{|c|c|c|c|c|}
\hline AOA (deg) & $\mathrm{Xcp}(\mathrm{V}=8)$ & $\mathrm{Xcp}(\mathrm{V}=12)$ & $\mathrm{Xcp}(\mathrm{V}=18)$ & \% Travel \\
\hline 0.0 & 0.808 & 0.835 & 0.855 & 0.833 \\
\hline 15.0 & 0.517 & 0.525 & 0.514 & 0.519 \\
\hline \% Travel & 29.0 & 31.0 & 34.1 & 31.4 \\
\hline
\end{tabular}

On average, there is a $5 \%$ decrease in the range of the center-of-pressure from the last slot configuration. Due to the close range with which the slots are achieving the stability of the center-of-pressure, the comparison will be continued with the extended convergence criteria for additional accuracy.

\subsection{Analysis of Secondary Convergence Data}

The optimal geometries of $x-15, w-2, d-30$ and $x-20, w-2, d-40$ were selected for additional comparison from the initial convergence criteria. The results were compared 
against the baseline data which was also recalculated using the extended criteria. A comparison of these results for $\mathrm{V}=18 \mathrm{~m} / \mathrm{s}$ can be seen in Table 9 .

Table 9: Comparison of Test Cases for $V=18 \mathrm{~m} / \mathrm{s}$

\begin{tabular}{|c|c|c|c|}
\hline AOA (deg) & Baseline & $\mathrm{x}-15, \mathrm{w}-2, \mathrm{~d}-30$ & $\mathrm{x}-20, \mathrm{w}-2, \mathrm{~d}-40$ \\
\hline 0.0 & 0.584 & 0.597 & 0.590 \\
\hline 15.0 & 0.423 & 0.444 & 0.452 \\
\hline \% Travel & 16.0 & 15.3 & 13.8 \\
\hline
\end{tabular}

As shown previously with the initial convergence data, the $\mathrm{x}-20$, w-2, d-40 slot configuration was able to control the travel of the center-of-pressure more effectively, compared to the $\mathrm{x}-15, \mathrm{w}-2, \mathrm{~d}-30$ geometry. At a velocity of $18 \mathrm{~m} / \mathrm{s}$, the $\mathrm{x}-20, \mathrm{w}-2, \mathrm{~d}-40$ slot configuration exhibited a $14 \%$ change on the center-of-pressure travel, whereas at a velocity of $8 \mathrm{~m} / \mathrm{s}$, the travel was reduced $6.5 \%$.

Since the position of the optimal slot is a midrange design value and the vertical angle is a maximum value, higher vertical angles were assessed to examine the range of the pitch stability. As previously mentioned with the initial convergence criteria, there were additional slot geometries tested for optimization. For the extended criteria, the x20, w-2, d-50 and x-20, w-2, d-60 configurations indicated an increase in travel as seen in Table 10.

Table 10: Comparison of Additional Test Cases for $V=18 \mathrm{~m} / \mathrm{s}$

\begin{tabular}{|c|c|c|c|}
\hline AOA (deg) & $\mathrm{x}-20, \mathrm{w}-2, \mathrm{~d}-40$ & $\mathrm{x}-20, \mathrm{w}-2, \mathrm{~d}-50$ & $\mathrm{x}-20, \mathrm{w}-2, \mathrm{~d}-60$ \\
\hline 0.0 & 0.590 & 0.632 & 0.629 \\
\hline 15.0 & 0.452 & 0.448 & 0.447 \\
\hline \% Travel & 13.8 & 18.4 & 18.2 \\
\hline
\end{tabular}

These results suggest that the $\mathrm{x}-20, \mathrm{w}-2, \mathrm{~d}-40$ configuration was most capable of controlling the travel of the center-of-pressure to within approximately $14 \%$ of the chord compared to the $50 \%$ of the chord experienced with the baseline. 


\subsection{Verification of Results}

In order to validate the results of this simulation, the baseline data from an unaltered Wortmann FX 63-137 had to be found. Due to the necessity for accuracy, the secondary convergence criteria were used for comparison. Examples of the lift coefficient residuals as well as the pressure distributions around the baseline for $\mathrm{V}=18 \mathrm{~m} / \mathrm{s}$ at varying angles of attack can be found in Appendix B.

The results presented from this simulation were comparatively analyzed against previous work performed both computationally and experimentally. In 2008, Smith computationally analyzed the aerodynamic characteristics of the Wortmann FX 63-137,

primarily the lift and drag coefficients. He found the trend of the lift coefficients as a function of angle of attack for various $\mathrm{h} / \mathrm{c}$ ratios. Smith validated his results by proving his method of model generation was accurate by creating simulated models of the NACA 4412 and comparing them to experimental results [22]. The experimental data for the FX 63-137 is taken from Abbot and Von Doenhoff which is freestream flow and therefore does not take into account ground effect. Figure 22 shows the comparison of the lift coefficients between the experimental, computational and current research with respect to the angle of attack. 


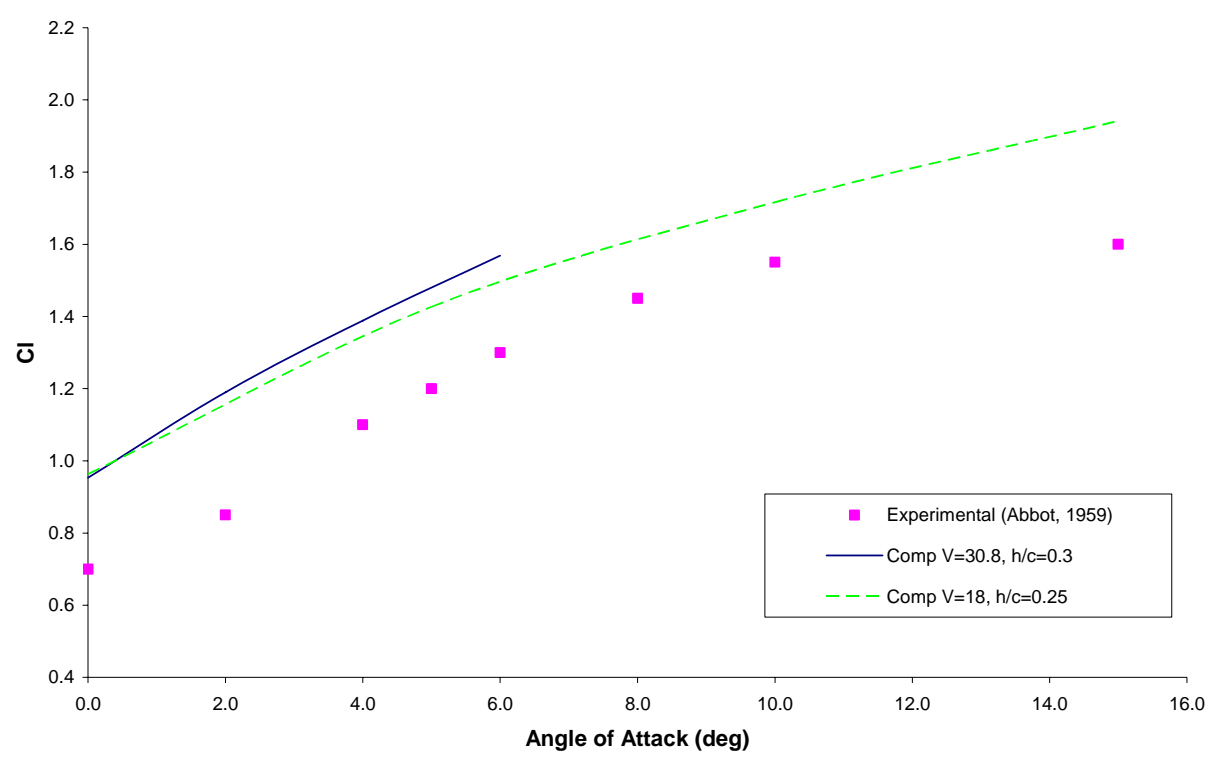

Figure 22: Comparative Analysis of Results with Previous Research

In Figure 22, it can be seen that the computational coefficients are $10 \%$ to $40 \%$ higher than the experimental values found in freestream. This is due to the pressure increase as the moving bodies approach the ground plane [22]. As seen in previous research, the lift coefficient is supplemented by its proximity to the ground, in which the optimal amount occurs at a height that is $25 \%$ of the chord length [2]. The data provided by Smith is slightly higher than the values found through this research due to the increased velocity used during that simulation.

In addition to the comparison of the ground effect data to the freestream experimental data, a comparison was necessary between the baseline operating in freestream flow and the experimental data provided by Abbot and Von Doenhoff. The baseline model was altered so that the airfoil was equally distance from all walls inside the model, permitting freestream simulation. The freestream baseline model was simulated with a velocity of $2 \mathrm{~m} / \mathrm{s}$. This velocity was found using Equation [2] and a 
Reynolds number of approximately 155,000. The given Reynolds number corresponds to that of the original experimental data. The comparison between the experimental and computational data can be seen in Figure 23.

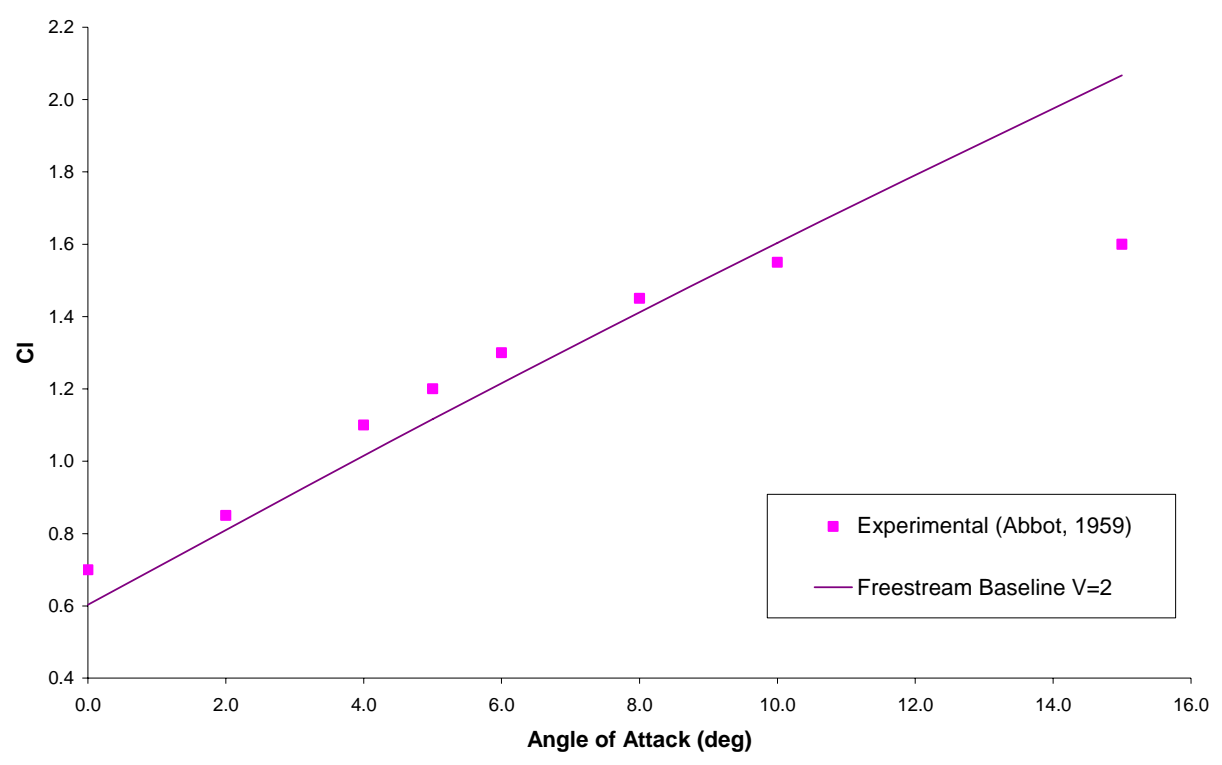

Figure 23: Comparative Analysis of Freestream Results

The freestream computational data follows similar trend lines to that of the experimental data. The discrepancy between the data is a potential result of the inherent differences that exist between the two methods of research. Computational research operates in an ideal environment with calculated effects as a result of applied forces. The data obtained from the simulation is the optimal result for that situation. Experimental data has the potential to include extraneous influences as a result of exposure to laboratory conditions. In addition, it operates in a semi-realistic atmosphere, which most closely relates to the actual operating environment. 


\section{Chapter 5.0 Conclusions}

Previous research showed that the center-of-pressure travel was only minimal at a steady angle of attack [22]. This research has shown positive results with respect to the effectiveness of slots, on passively controlling the movement of the center-of-pressure at varying angles of attack. Of the three positions along the chord line, the $20 \%$ position was most advantageous in stabilizing movement. Along with that characteristic, the 40 degree vertical slot was the most capable of the selected geometries in limiting the travel of the center-of-pressure and hence controlling pitch.

The ability of slot placement to passively control the center-of-pressure and hence the pitch stability has a wide range of applications outside that of a ground effect glider. Pitch instability is an inherent problem in many high speed technologies, including aircraft, missiles, and rockets. Through further research a more efficient manner of determining the proper slot configuration for its intended use can be found.

\subsection{Recommendations}

While the stability of the pitching moment has been positively impacted by the addition of passive controls, it could be further controlled through the potential use of more complex slot geometries, nose or trailing edge slaps, and/or tail placement. Further simulation is necessary to determine the implications of developing slot geometries that are tapered, curved, or possibly arced.

Nose and trailing edge flaps are active controls which could be dynamically used to control the pitch instabilities. These controls could be handled by the pilot which could potentially lead to problems with unskilled users, as is the case with the ground effect 
glider, or set on a feedback control system which would require less human interaction but instead need additional hardware to equip the gliders.

Tail design and placement could be an effective method for additionally controlling the travel of the center-of-pressure. As seen with the early ekranoplans, high $\mathrm{T}$ and $\mathrm{V}$ tails were useful in creating a counter moment, decreasing the positive pitching moment of the plane. 


\section{Chapter 6.0 References}

[1]. Williams, Kenneth. Concept of AirRay. January 3, 2007.

[2]. Rozhdestvensky, K.V., Aerodynamics of a Lifting System in Extreme Ground Effect. Springer, Berlin. 2000.

[3]. Scott, Jeff. “Ground Effect and WIG Vehicles” June 29, 2003.

<http://www.aerospaceweb.org/question/aerodynamics/q0130.shtml>

[4]. Ollila, R.G. "Historical Review of WIG Vehicles." Advanced Marine Vehicles Conference. AIAA-1979-2033. Baltimore, MD. 1979.

[5]. Raymond, A.E. “Ground Influence on Aerofoils.” 1921, NACA Technical Note 67.

[6]. Rozhdestvensky, K.V., "Lifting Line in Extreme Ground Effect." Proceedings of the EuroAvia Ground Effect Symposium. EuroAvia, Toulouse. 2001.

[7]. Cole, W. "The Pelican: A Big Bird for the Long Haul.” Boeing Frontiers Online. Vol. 1, Issue 5, September 2002. Accessed July 5, 2008.

[8]. Coulliette, C. and A. Plotkin. “Aerofoil ground effect revisited.” Aeronautical Journal. February 1996.

[9]. Borst, H.V. "Analysis of Vehicles with Wings Operating in Ground Effect.” Advanced Marine Vehicles Conference. AIAA-1979-2034. Baltimore, MD. 1979.

[10]. Ailor, W.H., and W.R. Eberle. "Configuration Effects on the Lift of a Body in Close Ground Proximity.” Journal of Aircraft, Vol. 13, No.8. August 1976.

[11]. Chawla, M.D., Edwards, L.C., and M.E. Franke. "Wind-Tunnel Investigation of Wing-in-Ground Effects.” Journal of Aircraft. Vol. 27, No. 4. April 1990.

[12]. Abbot, I.H. and A.E. Von Doenhoff. Theory of Wing Sections Including a Summary of Airfoil Data. Dover, NY. 1959.

[13]. Ranzenbach, R. and J. Barlow. "Cambered Airfoil in Ground Effect - An Experimental and Computational Study.” SAE International Congress \& Exposition. 960909. Detroit, MI. April 1996.

[14]. Ahmed, M.R., Kohama, Y., and T. Takasaki. "Aerodynamics of a NACA 4412 Airfoil in Ground Effect.” AIAA Journal. Vol. 45, No.1. January 2007. 
[15]. Hsuin, C.H. and C.K. Chen. "Aerodynamic Characteristics of a Two-Dimensional Airfoil with Ground Effect.” Journal of Aircraft. Vol. 33, No. 2. March-April 1996.

[16]. Barber, T.J., Leronardi, E., and R.D. Archer. “A Technical Note on the Appropriate CFD Boundary Conditions fort the Prediction of Ground Effect Aerodynamics.” The Aeronautical Journal. November 1999.

[17]. Chun, H.H. and R.H. Chang. "Turbulence Flow Simulation for Wings in Ground Effect with Two Ground Conditions: Fixed and Moving Ground.” International Journal of Maritime Engineering. 2003.

[18]. Landers, M.G., and L.M. Auman. "Experimental Investigation of Nose-Mounted Controls for a Hypersonic Missile.” AIAA Applied Aerodynamics Conference. AIAA-2001-2433. Anaheim, CA. 2001.

[19]. Appich, W.H., and J.R. Wittmeyer. "Aerodynamic effects of body slots on a guided projectile with cruciform surfaces." Atmospheric Flight Mechanics Conference. AIAA-1979-1658. Boulder, CO. 1979.

[20]. De Divitiis, N. "Performance and Stability of a Winged Vehicle in Ground Effect." Journal of Aircraft. Vol. 42, No. 1. February 2005.

[21]. Scientific Literature Digital Library. August 2008. $<$ http://www.aerodesign.ufsc.br/teoria/perfis/wort/wortmann.htm\#>

[22]. Smith, J. "Validation of an Airfoil in the Ground Effect Regime Using 2-D CFD Analysis." AIAA Aerodynamic Measurement Technology and Ground Testing Conference. AIAA-2008-4262. Seattle, WA. 2008.

[23]. Dunbar, Jill. “The Physics of a Race Car: Ground Effects.” August 27, 2001. $<$ http:www.nas.nasa.gov/About/Education/Racecar/physics_groundeffect.html>

[24]. Bertin, J. Aerodynamics for Engineers. Fourth Ed. Prentice Hall. Upper Saddle River, NJ. 2002.

[25]. “Fluent 6.2 User’s Guide”. Version 6.3. Ansys, Inc. 2005.

[26]. Celik, I.B. "Procedure for Estimation and Reporting of Discretization Error in CFD Applications.” Editorial Policy Statement on the Control of Numerical Accuracy. ASME Journal of Fluids Engineering. 2005. 


\section{Appendix A}

Spreadsheet of Aerodynamic Characteristics of All Models using Initial Criteria 


\begin{tabular}{|c|c|c|c|c|c|c|c|c|c|c|c|c|c|c|c|c|c|}
\hline$A O A$ & $\mathrm{~V}=$ & 8 & $\mathrm{~m} / \mathrm{s}$ & & & & $\mathrm{V}=$ & 12 & $\mathrm{~m} / \mathrm{s}$ & & & & $\mathrm{V}=$ & 18 & $\mathrm{~m} / \mathrm{s}$ & & \\
\hline deg & $F x$ & Fy & $\mathrm{Xcp}$ & $\mathrm{Cd}$ & $\mathrm{Cl}$ & $\mathrm{M}(0,0)$ & $\mathrm{Fx}$ & Fy & Xсp & $\mathrm{Cd}$ & $\mathrm{Cl}$ & $\mathrm{M}(0,0)$ & $F x$ & Fy & Хсp & $\mathrm{Cd}$ & $\mathrm{Cl}$ \\
\hline-3 & -0.22942 & \begin{tabular}{|l|}
5.894873 \\
\end{tabular} & 2.081271 & -0.00585 & \begin{tabular}{|l|}
0.150379 \\
\end{tabular} & 13.12673 & \begin{tabular}{|r|}
-2.9187 \\
\end{tabular} & 12.44267 & 1.989759 & \begin{tabular}{|l|}
-0.03309 \\
\end{tabular} & 0.141073 & \begin{tabular}{|l|}
26.69343 \\
\end{tabular} & \begin{tabular}{|l|}
-7.78061 \\
\end{tabular} & 29.25629 & 1.846607 & -0.039207 & \begin{tabular}{|l|}
0.147424 \\
\end{tabular} \\
\hline 0 & \begin{tabular}{|l|}
0.264758 \\
\end{tabular} & 12.9536 & 1.078667 & 0.006754 & \begin{tabular}{|l|}
0.331214 \\
\end{tabular} & 14.41001 & -1.28721 & 26.56545 & \begin{tabular}{|l|}
1.046993 \\
\end{tabular} & -0.01459 & 0.301196 & \begin{tabular}{|l|}
28.78215 \\
\end{tabular} & -3.33713 & 59.0631 & \begin{tabular}{|l|}
0.998674 \\
\end{tabular} & -0.016816 & 0.297622 \\
\hline 5 & 2.303904 & 30.30318 & 0.670587 & \begin{tabular}{|l|l|}
0.058773 \\
\end{tabular} & \begin{tabular}{|l|l|}
0.77304 \\
\end{tabular} & 20.86875 & -2.49194 & 116.5744 & \begin{tabular}{|l|l|}
0.42818 \\
\end{tabular} & -0.02825 & \begin{tabular}{|l|}
1.321705 \\
\end{tabular} & 50.18455 & 10.52184 & 261.7073 & \begin{tabular}{|l|}
0.428607 \\
\end{tabular} & 0.0530201 & \begin{tabular}{|l}
1.318757 \\
\end{tabular} \\
\hline 10 & \begin{tabular}{|l|}
7.639498 \\
\end{tabular} & 44.40972 & 0.592158 & 0.194885 & \begin{tabular}{|l|}
1.132901 \\
\end{tabular} & 27.00531 & \begin{tabular}{|l|}
10.67355 \\
\end{tabular} & 98.05578 & \begin{tabular}{|l|}
0.539162 \\
\end{tabular} & 0.121019 & \begin{tabular}{|l|}
1.111744 \\
\end{tabular} & 54.85443 & 21.89702 & 178.5156 & \begin{tabular}{|l|}
0.544075 \\
\end{tabular} & 0.1103402 & $\begin{array}{l}0.89955 \\
\end{array}$ \\
\hline 15 & 14.51514 & 55.21572 & 0.545114 & 0.370284 & 1.408564 & 31.11469 & \begin{tabular}{|l|}
24.88555 \\
\end{tabular} & 109.0325 & 0.522342 & 0.282149 & 1.236196 & 59.38673 & 46.97562 & 218.7815 & 0.496671 & 0.2367126 & 1.102452 \\
\hline
\end{tabular}
delta Xcp 153.6157 156.6941 141.8

\begin{tabular}{|c|c|c|c|c|c|c|c|c|c|c|c|c|c|c|c|c|c|}
\hline$A O A$ & $\mathrm{~V}=$ & 8 & $\mathrm{~m} / \mathrm{s}$ & & & & $\mathrm{V}=$ & 12 & $\mathrm{~m} / \mathrm{s}$ & & & & $\mathrm{V}=$ & 18 & $\mathrm{~m} / \mathrm{s}$ & & \\
\hline deg & $F x$ & Fy & Хсp & $\mathrm{Cd}$ & $\mathrm{Cl}$ & $\mathrm{M}(0,0)$ & Fx & Fy & Хср & $\mathrm{Cd}$ & $\mathrm{Cl}$ & $\mathrm{M}(0,0)$ & $F x$ & Fy & Xcp & $\mathrm{Cd}$ & $\mathrm{Cl}$ \\
\hline-3 & \begin{tabular}{|l|}
14.93663 \\
\end{tabular} & \begin{tabular}{l|l} 
& 6.987917 \\
\end{tabular} & 1.766164 & \begin{tabular}{|l|l|}
0.381036 \\
\end{tabular} & \begin{tabular}{|l|}
0.178263 \\
\end{tabular} & 12.50234 & \begin{tabular}{|l|}
12.02871 \\
\end{tabular} & 17.62314 & 1.499117 & 0.13638 & 0.199809 & 27.27992 & 14.13166 & 34.89177 & 1.540693 & 0.0712103 & 0.175821 \\
\hline 0 & 15.2758 & 16.24765 & 0.983043 & \begin{tabular}{|l}
0.389689 \\
\end{tabular} & \begin{tabular}{|l|l|}
0.414481 \\
\end{tabular} & 16.00109 & 14.15819 & 37.1175 & 0.90378 & \begin{tabular}{|l|}
0.160524 \\
\end{tabular} & \begin{tabular}{|l|}
0.420833 \\
\end{tabular} & 33.89155 & 18.67501 & \begin{tabular}{|l|}
76.37449 \\
\end{tabular} & 0.902672 & 0.0941044 & 0.384855 \\
\hline 5 & 22.90713 & 29.51882 & 0.671215 & 0.584366 & 0.753031 & 19.95183 & 25.80314 & 61.54111 & 0.6446 & 0.292553 & \begin{tabular}{|l|}
0.697745 \\
\end{tabular} & 40.20297 & 29.16976 & 128.1531 & 0.621875 & 0.146988 & 0.64577 \\
\hline 10 & 28.22623 & 43.14883 & 0.544103 & 0.720057 & 1.100736 & 23.71781 & \begin{tabular}{|l|}
41.8921 \\
\end{tabular} & 84.67029 & 0.540652 & 0.474967 & 0.959981 & 46.54608 & 60.41369 & 172.574 & 0.528672 & 0.3044278 & \begin{tabular}{|l|l|}
0.199809 \\
\end{tabular} \\
\hline 15 & \begin{tabular}{|l|}
34.66744 \\
\end{tabular} & 54.69908 & 0.509713 & 0.884373 & 1.395385 & 28.16869 & 59.68566 & 106.7101 & 0.507717 & 0.66537 & 1.209865 & 55.10809 & \begin{tabular}{|l|}
96.93889 \\
\end{tabular} & 212.105 & 0.49692 & 0.4884801 & \begin{tabular}{|l|}
1.068809 \\
\end{tabular} \\
\hline
\end{tabular}
delta Xcp 125.645 99.14 104.3772

\begin{tabular}{|c|c|c|c|c|c|c|c|c|c|c|c|c|c|c|c|c|c|}
\hline $\mathrm{AOA}$ & $\mathrm{V}=$ & 8 & $\mathrm{~m} / \mathrm{s}$ & & & & $\mathrm{V}=$ & 12 & $\mathrm{~m} / \mathrm{s}$ & & & & $\mathrm{V}=$ & 18 & $\mathrm{~m} / \mathrm{s}$ & & \\
\hline deg & $F x$ & Fy & $X c p$ & $\mathrm{Cd}$ & $\mathrm{Cl}$ & $\mathrm{M}(0,0)$ & Fx & Fy & Xсp & $\mathrm{Cd}$ & $\mathrm{Cl}$ & $M(0,0)$ & $F x$ & Fy & Xсp & $\mathrm{Cd}$ & $\mathrm{Cl}$ \\
\hline-3 & 12.94463 & $\begin{array}{l}7.27563 \\
\end{array}$ & 1.809201 & 0.33022 & 0.185603 & 13.06396 & \begin{tabular}{|l|}
14.37567 \\
\end{tabular} & \begin{tabular}{|c|}
17.72251 \\
\end{tabular} & 1.555657 & 0.162989 & 0.200935 & 28.02097 & 13.44297 & 39.3294 & 1.476874 & 0.0677398 & 0.198183 \\
\hline 0 & 12.1137 & 17.62997 & 0.953114 & 0.308964 & \begin{tabular}{|l|}
0.449744 \\
\end{tabular} & 16.73736 & \begin{tabular}{|l|}
12.60306 \\
\end{tabular} & \begin{tabular}{|l|}
39.15847 \\
\end{tabular} & 0.890654 & 0.142891 & \begin{tabular}{|l|}
0.443974 \\
\end{tabular} & 35.02706 & 14.07224 & \begin{tabular}{|l|}
81.62303 \\
\end{tabular} & \begin{tabular}{|l|}
0.880174 \\
\end{tabular} & 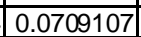 & 0.411303 \\
\hline 5 & 19.7491 & 28.31874 & 0.724377 & 0.503803 & 0.722417 & 20.57528 & \begin{tabular}{|l|}
6.063737 \\
\end{tabular} & 106.916 & 0.493866 & $\begin{array}{l}0.06875 \\
\end{array}$ & \begin{tabular}{|r|}
1.2122 \\
\end{tabular} & 53.48236 & 34.84608 & \begin{tabular}{|r|}
122.128 \\
\end{tabular} & 0.658899 & 0.1755912 & 0.615409 \\
\hline 10 & \begin{tabular}{|l|}
21.97621 \\
\end{tabular} & 44.66531 & 0.559552 & 0.560618 & \begin{tabular}{|l|}
1.139421 \\
\end{tabular} & 25.15454 & \begin{tabular}{|l|}
34.96455 \\
\end{tabular} & \begin{tabular}{|l|}
87.27024 \\
\end{tabular} & \begin{tabular}{|l|l|}
0.557069 \\
\end{tabular} & 0.396423 & \begin{tabular}{|l|}
0.989458 \\
\end{tabular} & 49.24747 & \begin{tabular}{|l|}
57.24619 \\
\end{tabular} & \begin{tabular}{|r}
176.463 \\
\end{tabular} & \begin{tabular}{|l|l|}
0.547001 \\
\end{tabular} & 0.2884666 & 0.889207 \\
\hline 15 & 29.47991 & 54.70034 & 0.535064 & 0.752039 & \begin{tabular}{|l|}
1.395417 \\
\end{tabular} & 29.49768 & \begin{tabular}{|l|l|}
48.32699 \\
\end{tabular} & \begin{tabular}{|l|}
106.2294 \\
\end{tabular} & 0.52819 & 0.547925 & 1.204415 & 56.95532 & 85.24146 & 212.7782 & \begin{tabular}{|l|}
0.515301 \\
\end{tabular} & 0.4295362 & 1.0722 \\
\hline
\end{tabular}




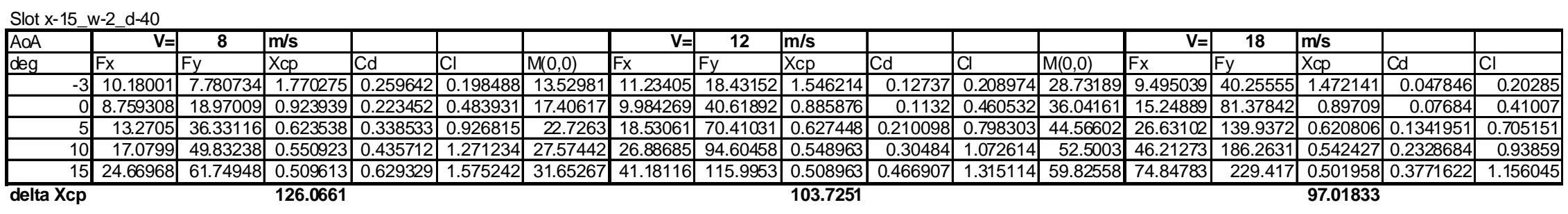

\begin{tabular}{|c|c|c|c|c|c|c|c|c|c|c|c|c|c|c|c|c|c|}
\hline$A O A$ & $\mathrm{~V}=$ & 8 & $\mathrm{~m} / \mathrm{s}$ & & & & $\mathrm{V}=$ & 12 & $\mathrm{~m} / \mathrm{s}$ & & & & $\mathrm{V}=$ & 18 & $\mathrm{~m} / \mathrm{s}$ & & \\
\hline deg & $\mathrm{Fx}$ & $\mathrm{Fy}$ & Xсp & $\mathrm{Cd}$ & $\mathrm{Cl}$ & $\mathrm{M}(0,0)$ & \begin{tabular}{|l|}
$F x$ \\
\end{tabular} & Fy & Xсp & $\mathrm{Cd}$ & $\mathrm{Cl}$ & $\mathrm{M}(0,0)$ & $\mathrm{Fx}$ & $\mathrm{Fy}$ & Xсp & $\mathrm{Cd}$ & $\mathrm{Cl}$ \\
\hline-3 & 17.0153 & \begin{tabular}{|l|}
6.706648 \\
\end{tabular} & 1.849809 & \begin{tabular}{|l|}
0.434064 \\
\end{tabular} & \begin{tabular}{|l|}
0.171088 \\
\end{tabular} & 12.52231 & 15.40322 & \begin{tabular}{|r|}
17.1611 \\
\end{tabular} & \begin{tabular}{|l|}
1.551217 \\
\end{tabular} & \begin{tabular}{|l|}
0.17464 \\
\end{tabular} & \begin{tabular}{|l|}
0.19457 \\
\end{tabular} & \begin{tabular}{|l|}
27.46275 \\
\end{tabular} & \begin{tabular}{|l|}
19.51196 \\
\end{tabular} & \begin{tabular}{|l|}
37.61233 \\
\end{tabular} & \begin{tabular}{|l|}
1.521531 \\
\end{tabular} & \begin{tabular}{|l|}
0.0983218 \\
\end{tabular} & 0.18953 \\
\hline 0 & 16.70297 & 15.71068 & 1.004904 & 0.426096 & \begin{tabular}{|l|}
0.400783 \\
\end{tabular} & \begin{tabular}{|l|}
15.79911 \\
\end{tabular} & 15.51742 & \begin{tabular}{|l|}
36.53626 \\
\end{tabular} & 0.913848 & 0.175934 & \begin{tabular}{|l|}
0.414243 \\
\end{tabular} & \begin{tabular}{|l|}
33.72351 \\
\end{tabular} & 19.57224 & \begin{tabular}{|l|}
75.38222 \\
\end{tabular} & 0.91599 & 0.0986255 & 0.379855 \\
\hline 5 & 23.4464 & 29.51099 & 0.662398 & 0.598123 & \begin{tabular}{|l|}
0.752831 \\
\end{tabular} & \begin{tabular}{|l|}
10.68496 \\
\end{tabular} & 27.96691 & 61.96445 & \begin{tabular}{|l|}
0.64315 \\
\end{tabular} & 0.317085 & 0.702545 & \begin{tabular}{|l|}
40.36178 \\
\end{tabular} & 31.0477 & \begin{tabular}{|l|}
131.2418 \\
\end{tabular} & \begin{tabular}{|l}
0.626353 \\
\end{tabular} & \begin{tabular}{|l|}
0.156451 \\
\end{tabular} & 0.661334 \\
\hline 10 & 27.62897 & 43.64031 & 0.550159 & 0.704821 & \begin{tabular}{|l|}
1.113273 \\
\end{tabular} & \begin{tabular}{|l|}
24.24328 \\
\end{tabular} & $\begin{array}{l}40.4781 \\
\end{array}$ & \begin{tabular}{|l|}
88.24282 \\
\end{tabular} & 0.54579 & 0.458935 & \begin{tabular}{|l|}
1.000485 \\
\end{tabular} & \begin{tabular}{|l|l|}
48.91064 \\
\end{tabular} & 61.3452 & \begin{tabular}{|l|}
179.3745 \\
\end{tabular} & \begin{tabular}{|l|l|}
0.539244 \\
\end{tabular} & 0.3091217 & 0.903878 \\
\hline 15 & 34.49553 & 55.64376 & 0.505566 & \begin{tabular}{|l|}
0.879988 \\
\end{tabular} & \begin{tabular}{|l|}
1.419484 \\
\end{tabular} & \begin{tabular}{|l|}
28.44309 \\
\end{tabular} & 58.02998 & \begin{tabular}{|l|}
108.9315 \\
\end{tabular} & 0.503104 & 0.657936 & \begin{tabular}{|l|}
1.235051 \\
\end{tabular} & \begin{tabular}{|l|}
55.78273 \\
\end{tabular} & 95.3365 & \begin{tabular}{|l|}
216.9008 \\
\end{tabular} & 0.489043 & \begin{tabular}{|l|l|}
0.4804056 \\
\end{tabular} & 1.092975 \\
\hline
\end{tabular}

\begin{tabular}{|c|c|c|c|c|c|c|c|c|c|c|c|c|c|c|c|c|c|}
\hline $\mathrm{AoA}$ & $\mathrm{V}=$ & 8 & $\mathrm{~m} / \mathrm{s}$ & & & & $\mathrm{V}=$ & 12 & $\mathrm{Im} / \mathrm{s}$ & & & & $\mathrm{v}=$ & 18 & $\mathrm{~m} / \mathrm{s}$ & & \\
\hline deg & $F x$ & Fy & Xcp & $\mathrm{Cd}$ & $\mathrm{Cl}$ & $\mathrm{M}(0,0)$ & $F x$ & Fy & Xcp & $\mathrm{Cd}$ & $\mathrm{Cl}$ & $M(0,0)$ & $F x$ & Fy & Xсp & $\mathrm{Cd}$ & $\mathrm{Cl}$ \\
\hline-3 & 14.03323 & \begin{tabular}{l|l}
3.754353 \\
3
\end{tabular} & 2.175606 & 0.357991 & 0.156795 & 12.43368 & 14.24879 & 16.23352 & 1.648373 & 0.161551 & 0.184053 & 27.33884 & 12.80814 & 38.24095 & \begin{tabular}{l|l}
1.506421 \\
\end{tabular} & 0.0645409 & 0.192698 \\
\hline 0 & 13.58879 & 15.20598 & 1.027196 & 0.346653 & 0.387908 & 15.54663 & 13.36324 & 35.17216 & 0.961424 & 0.151511 & \begin{tabular}{|l|}
0.398777 \\
\end{tabular} & 33.11577 & 26.57725 & 69.18215 & \begin{tabular}{l|l}
0.908539 \\
\end{tabular} & 0.1339242 & 0.348612 \\
\hline 5 & \begin{tabular}{|l|}
16.27911 \\
\end{tabular} & $\begin{array}{l}30.82989 \\
\end{array}$ & 0.644437 & \begin{tabular}{|l|}
0.415283 \\
\end{tabular} & \begin{tabular}{|l|}
0.786477 \\
\end{tabular} & 19.94364 & 23.46362 & 62.28541 & $\begin{array}{l}0.639078 \\
\end{array}$ & 0.266027 & 0.761838 & 40.19837 & 31.23227 & \begin{tabular}{|l|}
132.3439 \\
\end{tabular} & \begin{tabular}{|l|}
0.624611 \\
\end{tabular} & 0.1573811 & 0.666888 \\
\hline 10 & \begin{tabular}{|l|}
21.77196 \\
\end{tabular} & 37.57371 & 0.558834 & \begin{tabular}{|l|}
0.555407 \\
\end{tabular} & \begin{tabular}{|l|}
0.958513 \\
\end{tabular} & 21.23849 & 33.0356 & 78.64789 & 0.546592 & 0.374553 & 0.891699 & 43.78903 & 52.19377 & \begin{tabular}{|l|}
165.2119 \\
\end{tabular} & \begin{tabular}{l|l} 
& 0.53058 \\
\end{tabular} & 0.2630072 & 0.823511 \\
\hline 15 & 29.00309 & 58.10668 & 0.51767 & 0.739875 & 1.482313 & 30.33701 & 49.07025 & 114.3497 & 0.51719 & 0.556352 & 1.296482 & 60034054 & 87.32536 & 227.5331 & \begin{tabular}{|l}
0.508409 \\
\end{tabular} & 0.4400371 & 1.146551 \\
\hline
\end{tabular}

Slot $x-20 \quad w-2 \quad d-40$

\begin{tabular}{|c|c|c|c|c|c|c|c|c|c|c|c|c|c|c|c|c|c|}
\hline $\mathrm{AOA}$ & $\mathrm{V}=$ & 8 & $\mathrm{~m} / \mathrm{s}$ & & & & $\mathrm{V}=$ & 12 & $\mathrm{~m} / \mathrm{s}$ & & & & $\mathrm{V}=$ & 18 & $\mathrm{~m} / \mathrm{s}$ & & \\
\hline deg & $\mathrm{Fx}$ & Fy & Xсp & $\mathrm{Cd}$ & $\mathrm{Cl}$ & $\mathrm{M}(0,0)$ & $\mathrm{Fx}$ & Fy & Xсp & $\mathrm{Cd}$ & $\mathrm{Cl}$ & $\mathrm{M}(0,0)$ & $\mathrm{Fx}$ & Fy & Xсp & $\mathrm{Cd}$ & $\mathrm{Cl}$ \\
\hline-3 & \begin{tabular}{|l|}
9.997225 \\
\end{tabular} & 76925514 & 1.795469 & 0.255031 & \begin{tabular}{|l|}
0.196239 \\
\end{tabular} & 13.57397 & \begin{tabular}{|c|}
9.890175 \\
\end{tabular} & 18.56464 & 1.534888 & 0.112134 & 0.210482 & 28.74102 & 10.33348 & 39.06288 & 1.151107 & 0.0520709 & 0.19684 \\
\hline 0 & 7.197561 & 9.047909 & 0.903842 & 0.183611 & \begin{tabular}{|l|}
0.485916 \\
\end{tabular} & 17.12399 & 7.440195 & 可 39.82855 & \begin{tabular}{|l|}
0.880549 \\
\end{tabular} & 0.084356 & 0.451571 & \begin{tabular}{|l|}
35.17681 \\
\end{tabular} & \begin{tabular}{|l|}
11.56758 \\
\end{tabular} & 77.71305 & \begin{tabular}{|l|}
0.898516 \\
\end{tabular} & 0.0528964 & 39160013 \\
\hline 5 & \begin{tabular}{|l|}
12.40002 \\
\end{tabular} & 36.39765 & 0.617554 & 0.316327 & \begin{tabular}{|l|}
0.928511 \\
\end{tabular} & 22.52595 & 18.11926 & \begin{tabular}{l|l}
70.2414 \\
\end{tabular} & \begin{tabular}{|l|}
0.618464 \\
\end{tabular} & 0.205434 & \begin{tabular}{|l}
0.796388 \\
\end{tabular} & \begin{tabular}{|l|l|}
43.76185 \\
\end{tabular} & \begin{tabular}{|l|}
28.41597 \\
\end{tabular} & 139.6806 & \begin{tabular}{|l|}
0.615682 \\
\end{tabular} & 0.1431895 & 0.703858 \\
\hline 10 & 17.15136 & 48.94136 & 0.546138 & \begin{tabular}{|l|l}
0.437535 \\
\end{tabular} & \begin{tabular}{|l|}
1.248504 \\
\end{tabular} & 26.86591 & 27.37428 & 93.40309 & \begin{tabular}{|l|}
0.543772 \\
\end{tabular} & 0.310337 & 1.058992 & \begin{tabular}{|l|}
51.35905 \\
\end{tabular} & 47.0485 & 185.2113 & \begin{tabular}{|l|}
0.536531 \\
\end{tabular} & 0.2370799 & 0.933289 \\
\hline 15 & 25.4901 & 62.99659 & 0.521908 & 0.650258 & \begin{tabular}{|l|}
1.607056 \\
\end{tabular} & 33.05586 & 43.5543 & \begin{tabular}{|l|l} 
& 121.2873 \\
\end{tabular} & 0.520671 & 0.493813 & 1.375139 & 63.89118 & \begin{tabular}{|l|}
78.39645 \\
\end{tabular} & 238.9312 & 0.512361 & 0.3950438 & 1.203987 \\
\hline & & & 127.3561 & & & & & & 101.4217 & & & & & & 63.87454 & & \\
\hline
\end{tabular}




\begin{tabular}{|c|c|c|c|c|c|c|c|c|c|c|c|c|c|c|c|c|c|}
\hline$A O A$ & $\mathrm{~V}=$ & 8 & $\mathrm{~m} / \mathrm{s}$ & & & & $\mathrm{V}=$ & 12 & $\mathrm{~m} / \mathrm{s}$ & & & & $\mathrm{V}=$ & 18 & $\mathrm{~m} / \mathrm{s}$ & & \\
\hline deg & $\mathrm{Fx}$ & Fy & Xсp & $\mathrm{Cd}$ & $\mathrm{Cl}$ & $\mathrm{M}(0,0)$ & $\mathrm{Fx}$ & Fy & Xcp & $\mathrm{Cd}$ & $\mathrm{Cl}$ & $\mathrm{M}(0,0)$ & $\mathrm{Fx}$ & Fy & Xсp & $\mathrm{Cd}$ & $\mathrm{Cl}$ \\
\hline-3 & \begin{tabular}{|l}
18.3074 \\
\end{tabular} & \begin{tabular}{|l|}
5.572308 \\
\end{tabular} & \begin{tabular}{|l}
2.157307 \\
\end{tabular} & 0.467025 & \begin{tabular}{|l|l|}
0.142151 \\
\end{tabular} & 12.27945 & 14.42736 & 16.29903 & 1.619354 & \begin{tabular}{|l}
0.163576 \\
\end{tabular} & \begin{tabular}{|l|l|}
0.184796 \\
\end{tabular} & 27.46504 & 15.73789 & 34.55114 & \begin{tabular}{|l}
1.600857 \\
\end{tabular} & 0.0793041 & \begin{tabular}{|l|}
0.174105 \\
\end{tabular} \\
\hline 0 & 14.52935 & 16.03799 & 1.006161 & 0.370647 & \begin{tabular}{|l|l|}
0.409132 \\
\end{tabular} & 16.23281 & 12.56406 & 35.59004 & 0.945416 & 0.14245 & \begin{tabular}{|l|}
0.403515 \\
\end{tabular} & \begin{tabular}{|l|}
34.11582 \\
\end{tabular} & 17.72404 & 71.92482 & \begin{tabular}{|l|}
0.947712 \\
\end{tabular} & 0.0893124 & 0.362433 \\
\hline 5 & 20.59582 & 29.58121 & 0.687547 & 0.525404 & \begin{tabular}{|l}
0.754623 \\
\end{tabular} & 20.53698 & 23.30306 & 62.08649 & 0.660894 & 0.264207 & \begin{tabular}{|l|}
0.703928 \\
\end{tabular} & 41.66514 & 26.44188 & \begin{tabular}{|l|}
122.7555 \\
\end{tabular} & \begin{tabular}{|l|l|}
0.638274 \\
\end{tabular} & 0.133242 & 0.618571 \\
\hline 10 & 28.3368 & 47.34163 & 0.562984 & 0.722878 & 1.207695 & 26.92018 & 45.03598 & \begin{tabular}{|l|l} 
& 91.9172 \\
\end{tabular} & 0.563164 & 0.510612 & \begin{tabular}{|l|}
1.042145 \\
\end{tabular} & 52.57659 & \begin{tabular}{|l|}
69.96846 \\
\end{tabular} & 186.1061 & \begin{tabular}{|l}
0.555484 \\
\end{tabular} & 0.3525748 & 0.937799 \\
\hline 15 & 36.74062 & 61.90197 & 0.524077 & 0.937261 & 1.579132 & 32.79141 & 61.53052 & 120.163 & 0.523063 & 0.697625 & 1.362393 & 63.90372 & 103.5894 & 236.816 & 0.514832 & 0.5219926 & 1.193329 \\
\hline
\end{tabular}

\begin{tabular}{|c|c|c|c|c|c|c|c|c|c|c|c|c|c|c|c|c|c|}
\hline $\mathrm{AoA}$ & $\mathrm{V}=$ & 8 & $\mathrm{~m} / \mathrm{s}$ & & & & $\mathrm{V}=$ & 12 & $\mathrm{~m} / \mathrm{s}$ & & & & $\mathrm{V}=$ & 18 & $\mathrm{~m} / \mathrm{s}$ & & \\
\hline $\operatorname{deg}$ & $F x$ & Fy & Xсp & $\mathrm{Cd}$ & $\mathrm{Cl}$ & $\mathrm{M}(0,0)$ & $F x$ & Fy & Хсp & $\mathrm{Cd}$ & $\mathrm{Cl}$ & $\mathrm{M}(0,0)$ & $F x$ & Fy & Хсp & $\mathrm{Cd}$ & $\mathrm{Cl}$ \\
\hline-3 & 14.92994 & 5.90526 & 2.169193 & 0.380866 & \begin{tabular}{|l|}
0.150644 \\
\end{tabular} & 12.68907 & 15.88593 & 15.94811 & 1.707089 & 0.180113 & 0.180818 & 27.73876 & 11.47142 & 36.95039 & \begin{tabular}{|l|}
1.562836 \\
\end{tabular} & \begin{tabular}{|l|}
0.0578051 \\
\end{tabular} & \begin{tabular}{|l}
0.186195 \\
\end{tabular} \\
\hline 0 & 11.8312 & 17.98143 & 0.950937 & 0.301816 & 0.45871 & 17.05924 & 13.59003 & \begin{tabular}{l|l}
37.99374 \\
\end{tabular} & 0.923464 & 0.154082 & 0.430768 & 35.29615 & \begin{tabular}{|l|}
13.83031 \\
\end{tabular} & 78.20041 & 0.909975 & 0.0696916 & 0.394056 \\
\hline 5 & 17.12283 & 33.48622 & 0.642111 & 0.436807 & 0.85424 & 21.62426 & 24.71015 & 67.25452 & 0.635887 & 0.28016 & \begin{tabular}{|l|}
0.762523 \\
\end{tabular} & \begin{tabular}{|l|}
43.22437 \\
\end{tabular} & 33.98421 & 138.8055 & \begin{tabular}{|l|}
0.625824 \\
\end{tabular} & 0.1712482 & 0.699448 \\
\hline 10 & \begin{tabular}{|l|}
22.10801 \\
\end{tabular} & 47.4631 & 0.55722 & 0.56398 & \begin{tabular}{|l|}
1.210793 \\
\end{tabular} & 26.67106 & 35.84894 & $\begin{array}{l}93.5324 \\
9\end{array}$ & 0.556676 & 0.406451 & 1.060458 & 52.79138 & 57.87862 & 187.2354 & \begin{tabular}{|l|}
0.548364 \\
\end{tabular} & 0.2916534 & 0.943489 \\
\hline 15 & 15.97871 & 59.31005 & 0.519527 & 0.40762 & 1.513011 & $\begin{array}{l}31.7224 \\
\end{array}$ & 48.27808 & \begin{tabular}{l|l}
116.8137 \\
\end{tabular} & 0.518716 & 0.547371 & 1.324418 & 61.56638 & \begin{tabular}{|l|}
83.3888 \\
\end{tabular} & 230.7396 & 0.508605 & 0.4202005 & 1.162709 \\
\hline delta Xcp & & & 164.9666 & & & & & & 118.8373 & & & & & & 105.4231 & & \\
\hline \multicolumn{18}{|c|}{ Slot $x-25 w-2 \quad d-40$} \\
\hline$A O A$ & $\mathrm{~V}=$ & 8 & $\mathrm{~m} / \mathrm{s}$ & & & & $\mathrm{V}=$ & 12 & $\mathrm{~m} / \mathrm{s}$ & & & & $\mathrm{V}=$ & 18 & $\mathrm{~m} / \mathrm{s}$ & & \\
\hline deg & $F x$ & Fy & Xсp & $\mathrm{Cd}$ & $\mathrm{Cl}$ & $\mathrm{M}(0,0)$ & $F x$ & Fy & Xсp & $\mathrm{Cd}$ & $\mathrm{Cl}$ & $\mathrm{M}(0,0)$ & $F x$ & Fy & Xсp & $\mathrm{Cd}$ & $\mathrm{Cl}$ \\
\hline-3 & \begin{tabular}{|l}
10.56398 \\
\end{tabular} & 6.660257 & 2.053294 & 0.269489 & 0.169905 & 13.39589 & 11.85708 & 16.50425 & 1.7328 & 0.134434 & 0.18123 & 28.87027 & 10.34271 & 36.22153 & 1.627378 & 0.0521175 & 0.182522 \\
\hline 0 & 9.096072 & 18.6392 & 0.945148 & 0.232043 & \begin{tabular}{|l|}
0.47549 \\
\end{tabular} & 17.52587 & 11.05162 & 38.98403 & 0.924732 & 0.125302 & 0.441996 & 36.18284 & \begin{tabular}{|l|}
16.03884 \\
\end{tabular} & 77.65038 & \begin{tabular}{|l|}
0.933538 \\
\end{tabular} & \begin{tabular}{|l}
0.0808206 \\
\end{tabular} & 0.391284 \\
\hline 5 & \begin{tabular}{|l|}
12.08502 \\
\end{tabular} & 36.26067 & 0.623482 & 0.308291 & 0.925017 & 22.69995 & 17.61174 & 70.22436 & $\begin{array}{l}0.626757 \\
\end{array}$ & 0.19968 & \begin{tabular}{|l}
0.796195 \\
\end{tabular} & \begin{tabular}{|l|}
44.42328 \\
\end{tabular} & \begin{tabular}{|l|}
27.14362 \\
\end{tabular} & 139.1335 & 0.62478 & \begin{tabular}{|l|}
0.1367781 \\
\end{tabular} & 0.701101 \\
\hline 10 & 17.0249 & 50.55498 & \begin{tabular}{l|l}
0.558713 \\
\end{tabular} & 0.434309 & 1.289668 & 28.42015 & 27.2519 & 96.48539 & 0.558368 & 0.308978 & 1.093939 & \begin{tabular}{|l|}
54.53434 \\
\end{tabular} & 47.67594 & 191.908 & \begin{tabular}{|l|}
0.552379 \\
\end{tabular} & 0.2402416 & 0.967034 \\
\hline 15 & \begin{tabular}{|l|}
24.88887 \\
\end{tabular} & 62.99703 & \begin{tabular}{|l|l|} 
& 0.527897 \\
\end{tabular} & 0.63492 & \begin{tabular}{|l|}
1.607067 \\
\end{tabular} & 33.50128 & 42.28399 & \begin{tabular}{l|l|}
121.1881
\end{tabular} & 0.525091 & 0.47941 & 1.374014 & 64.49981 & 76.2587 & 239.0793 & \begin{tabular}{|l|}
0.515464 \\
\end{tabular} & 0.3842716 & 1.204733 \\
\hline
\end{tabular}




\section{Appendix B}

Pressure Distribution around Baseline Airfoils at V=18 m/s Convergence of Lift Coefficient of Baseline Airfoils at V=18 m/s 


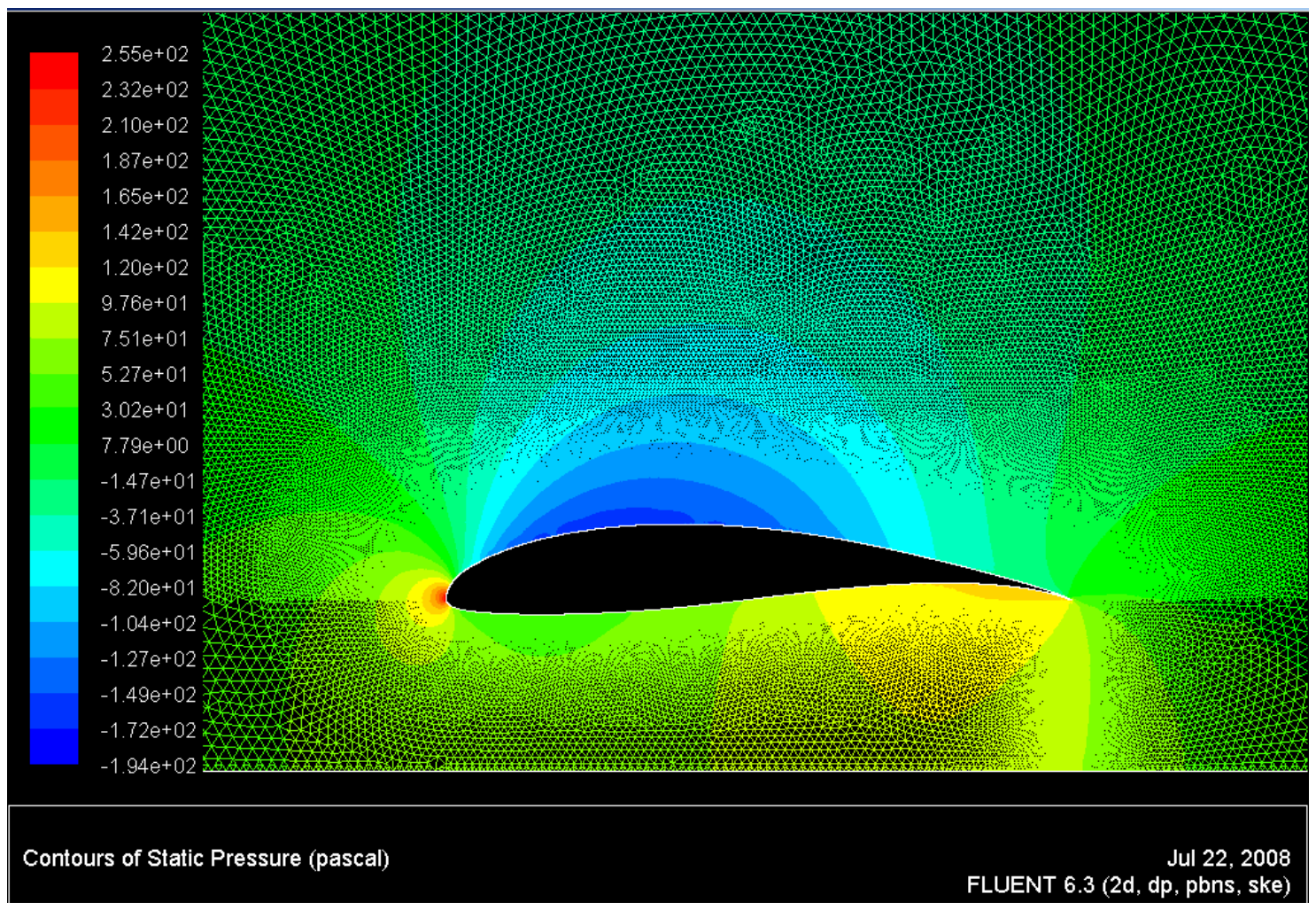

Figure 24: Baseline A-0, V-18 - Pressure Distribution

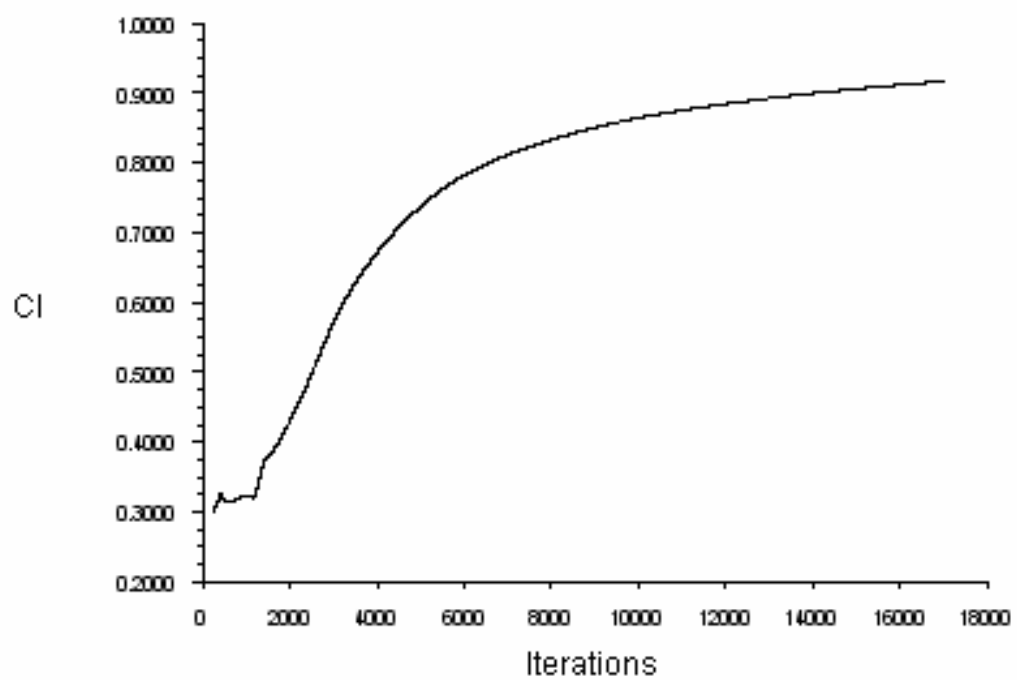

Figure 25: Baseline A-0, V-18 - Convergence of Lift Coefficient 


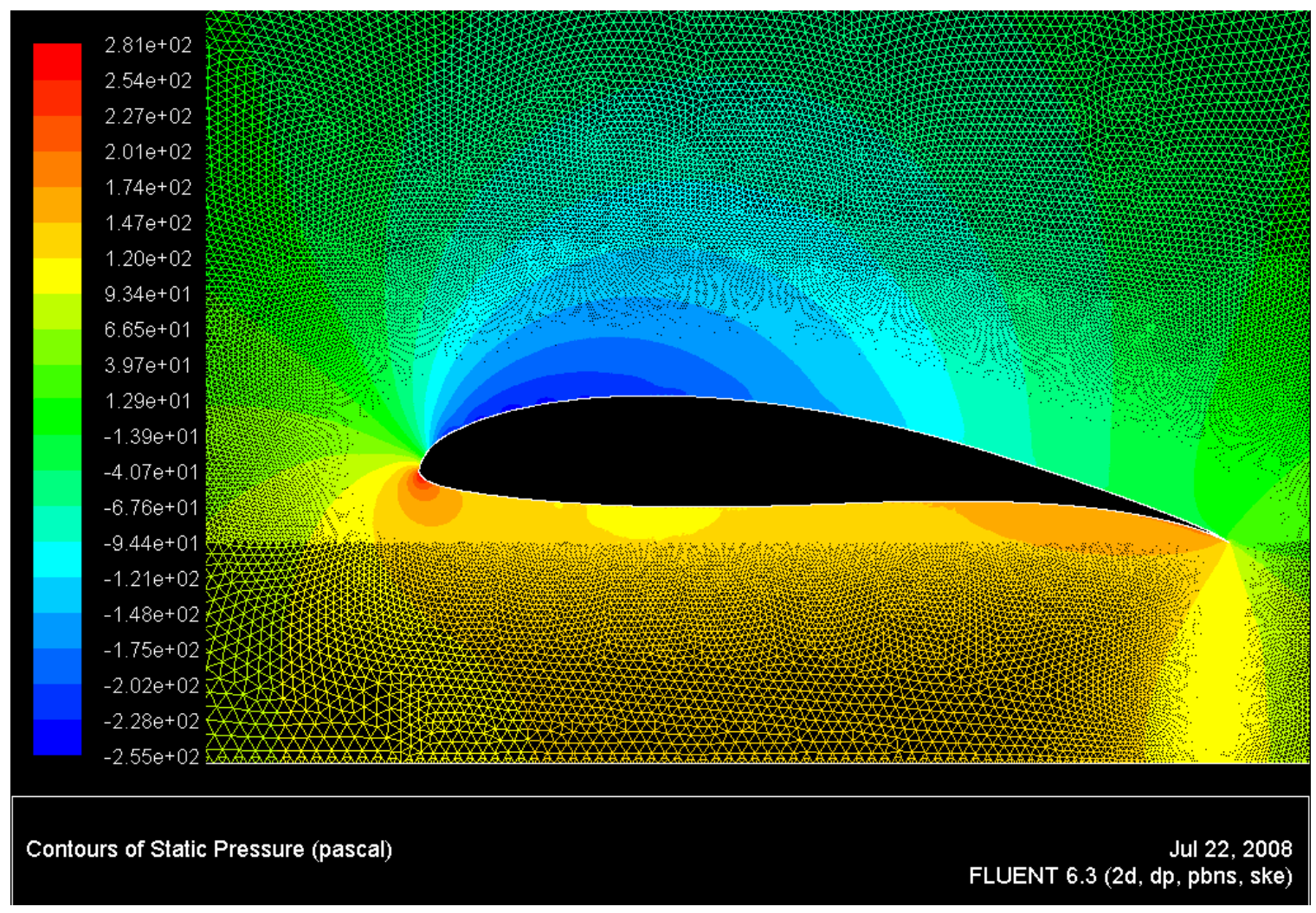

Figure 26: Baseline A-5, V-18 - Pressure Distribution

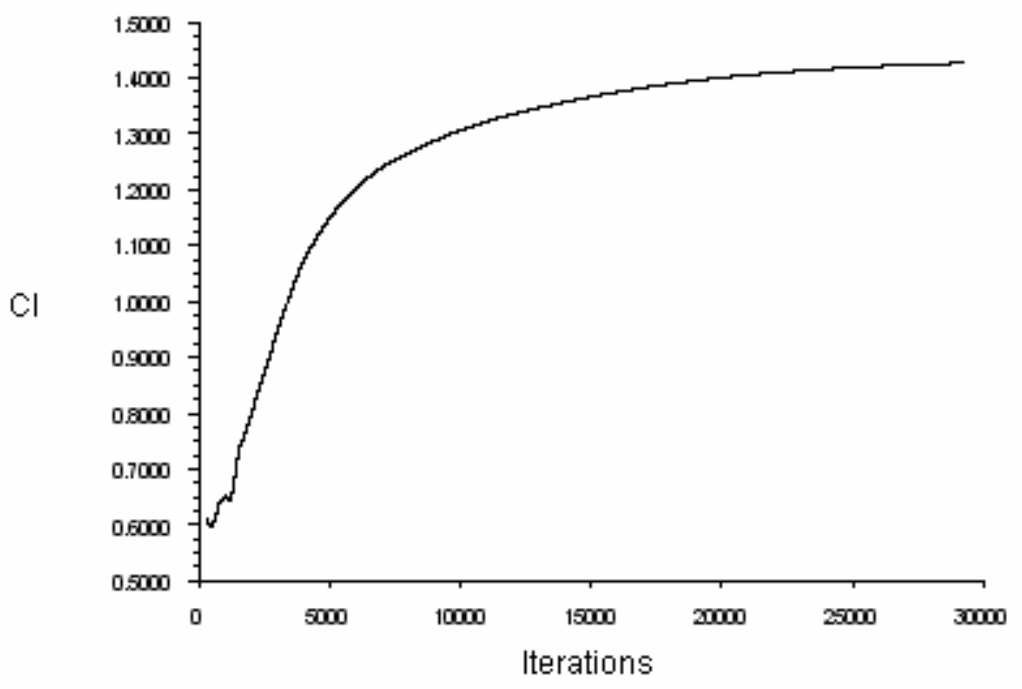

Figure 27: Baseline A-5, V-18 - Convergence of Lift Coefficient 


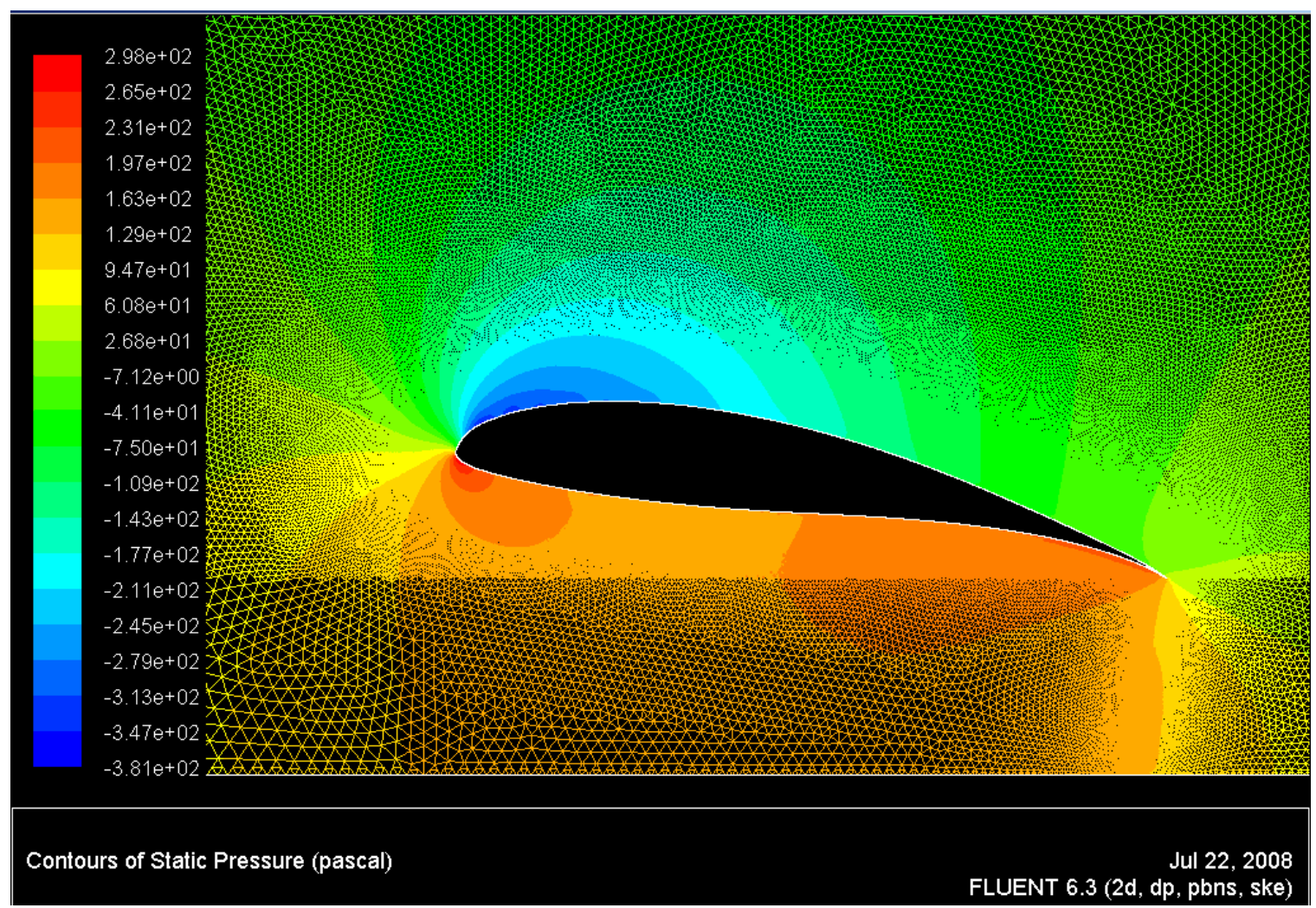

Figure 28: Baseline A-10, V-18 - Pressure Distribution

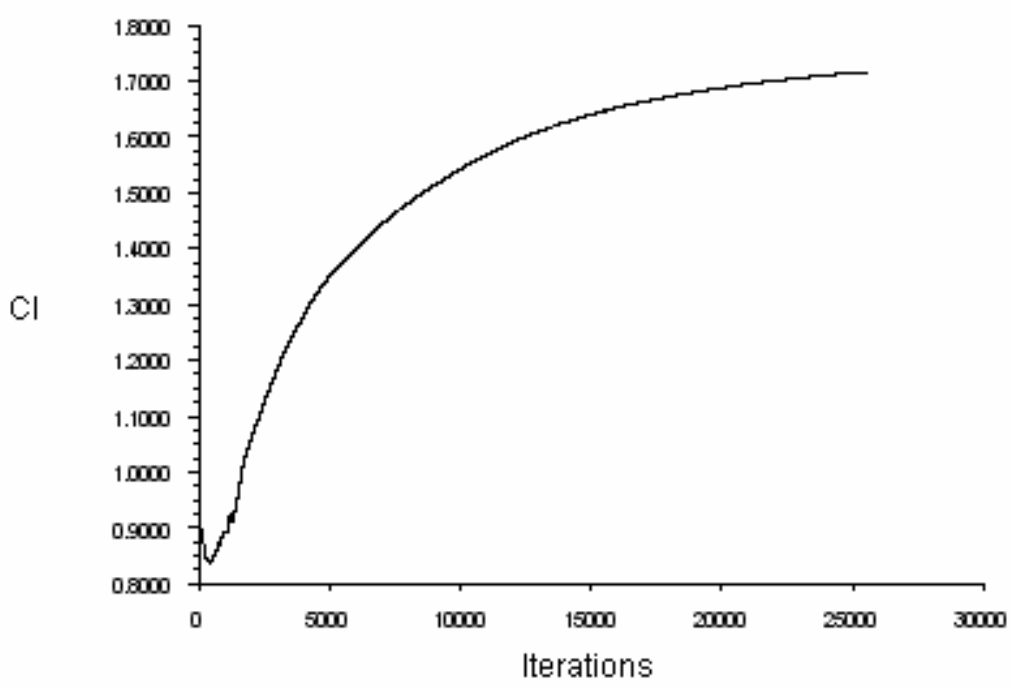

Figure 29: Baseline A-10, V-18 - Convergence of Lift Coefficient 


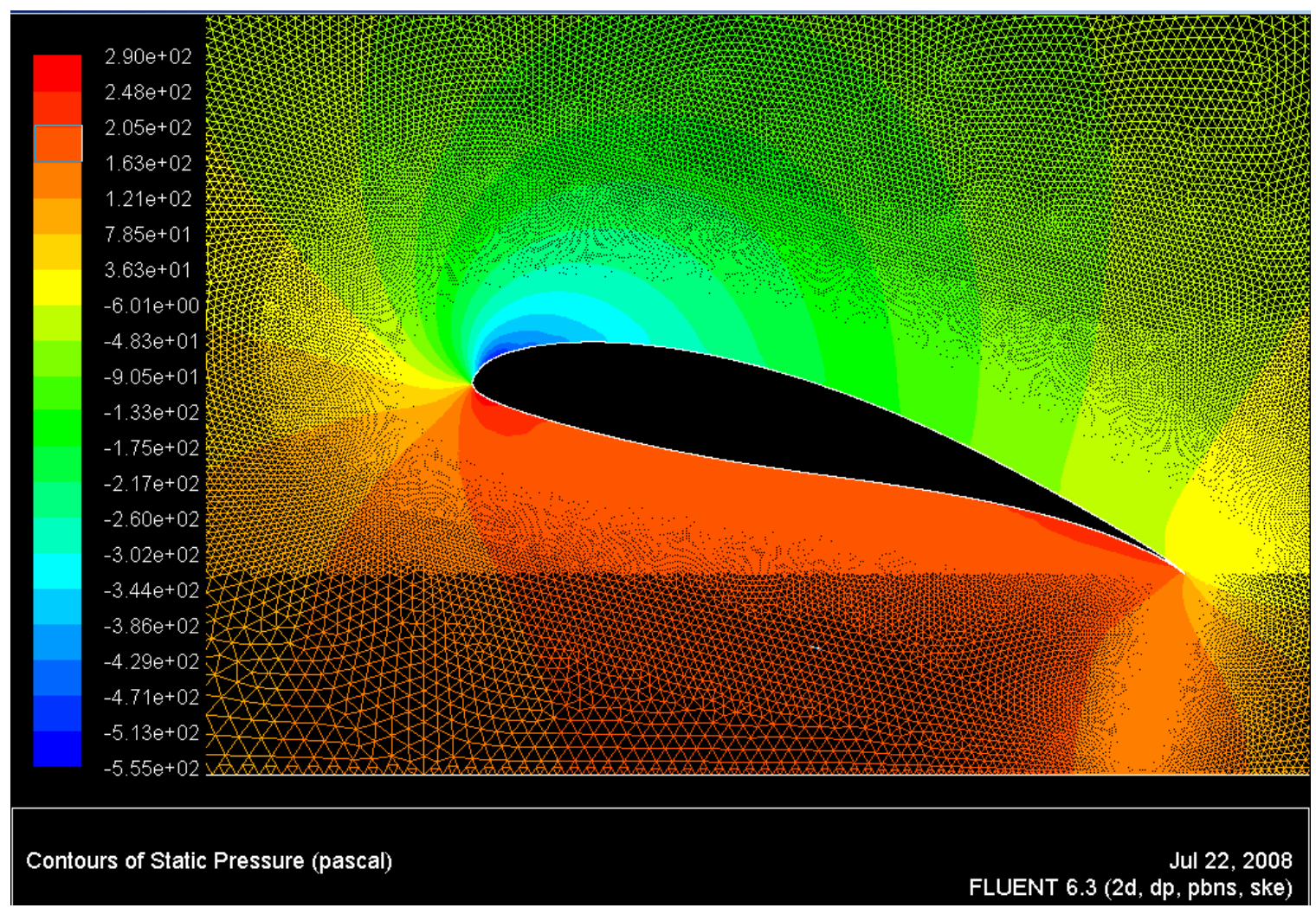

Figure 30: Baseline A-15, V-18 - Pressure Distribution

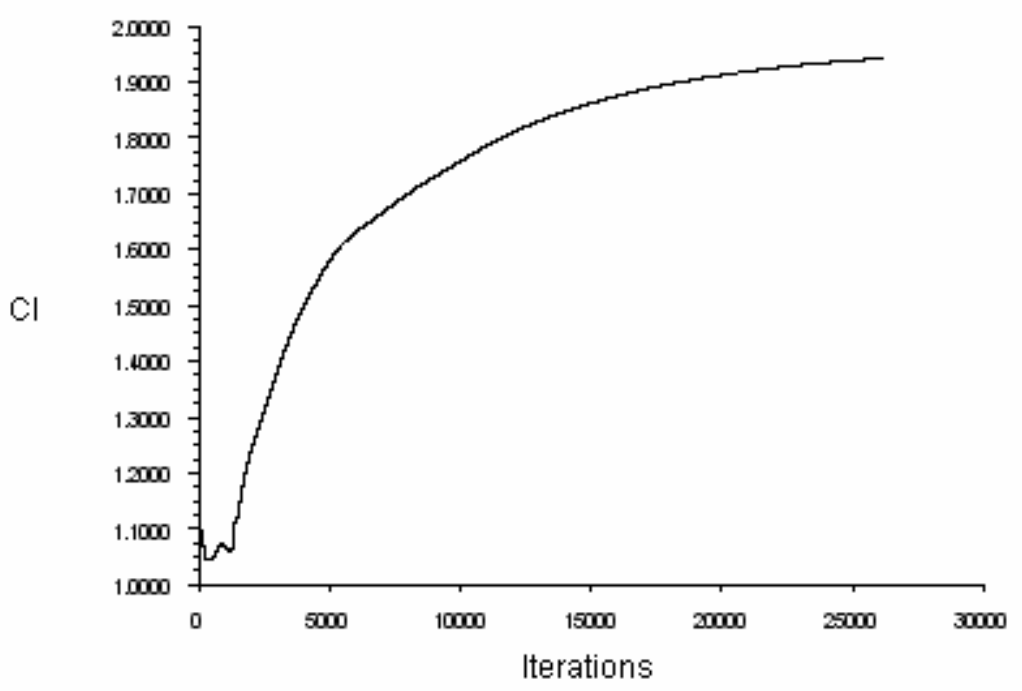

Figure 31: Baseline A-15, V-18 - Convergence of Lift Coefficient 


\section{Appendix C}

Model Pressure Distribution around x-15, d-30, w-2 Airfoils at V=18 m/s Convergence of Lift Coefficient of x-15, d-30, w-2 Airfoils at V=18 m/s Model Pressure Distribution around $x-20, d-40, w-2$ Airfoils at V=18 m/s Convergence of Lift Coefficient of x-20, d-40, w-2 Airfoils at V=18 m/s

(Added when simulations are complete) 